\title{
Mass spectrometry imaging for clinical research - latest developments, applications, and current limitations
}

Citation for published version (APA):

Vaysse, P-M., Heeren, R. M. A., Porta, T., \& Balluff, B. (2017). Mass spectrometry imaging for clinical research - latest developments, applications, and current limitations. Analyst, 142(15), 2690-2712. https://doi.org/10.1039/c7an00565b

Document status and date:

Published: 07/08/2017

DOI:

10.1039/c7an00565b

Document Version:

Publisher's PDF, also known as Version of record

Document license:

Taverne

Please check the document version of this publication:

- A submitted manuscript is the version of the article upon submission and before peer-review. There can be important differences between the submitted version and the official published version of record.

People interested in the research are advised to contact the author for the final version of the publication, or visit the DOI to the publisher's website.

- The final author version and the galley proof are versions of the publication after peer review.

- The final published version features the final layout of the paper including the volume, issue and page numbers.

Link to publication

\footnotetext{
General rights rights.

- You may freely distribute the URL identifying the publication in the public portal. please follow below link for the End User Agreement:

www.umlib.nl/taverne-license

Take down policy

If you believe that this document breaches copyright please contact us at:

repository@maastrichtuniversity.nl

providing details and we will investigate your claim.
}

Copyright and moral rights for the publications made accessible in the public portal are retained by the authors and/or other copyright owners and it is a condition of accessing publications that users recognise and abide by the legal requirements associated with these

- Users may download and print one copy of any publication from the public portal for the purpose of private study or research.

- You may not further distribute the material or use it for any profit-making activity or commercial gain

If the publication is distributed under the terms of Article 25fa of the Dutch Copyright Act, indicated by the "Taverne" license above, 


\section{Check for updates}

Cite this: Analyst, 2017, 142, 2690

\title{
Mass spectrometry imaging for clinical research - latest developments, applications, and current limitations
}

\author{
Pierre-Maxence Vaysse, (iD Ron M. A. Heeren, (D) Tiffany Porta (D) * $\uparrow$ and \\ Benjamin Balluff (iD *†
}

\begin{abstract}
Mass spectrometry is being used in many clinical research areas ranging from toxicology to personalized medicine. Of all the mass spectrometry techniques, mass spectrometry imaging (MSI), in particular, has continuously grown towards clinical acceptance. Significant technological and methodological improvements have contributed to enhance the performance of MSI recently, pushing the limits of throughput, spatial resolution, and sensitivity. This has stimulated the spread of MSI usage across various biomedical research areas such as oncology, neurological disorders, cardiology, and rheumatology, just to name a few. After highlighting the latest major developments and applications touching all aspects of translational research (i.e. from early pre-clinical to clinical research), we will discuss the present challenges in translational research performed with MSI: data management and analysis, molecular coverage and identification capabilities, and finally, reproducibility across multiple research centers, which is the largest remaining obstacle in moving MSI towards clinical routine.
\end{abstract}

Received 5th April 2017

Accepted 11th June 2017

DOI: $10.1039 / c 7 a n 00565 b$

rsc.li/analyst microscopic dissection (micro-dissection) or other cell-enrichment procedures preceding the omics analyses. ${ }^{5,6}$ These methods provide unrivalled analytical depth and sensitivity, but are tedious, time consuming, and/or require previous knowledge of the cellular entities of interest; and some may even destroy the histological context of the sample.

Mass spectrometry imaging (MSI) is a microscopy technique that can directly analyse tissue sections without the need to destroy sample integrity. ${ }^{7}$ All MSI-based techniques rely on the discrete or continuous movement of a desorption and ionization probe across a sample's surface. ${ }^{8}$ At each measurement coordinate, molecules present at the sample's surface are desorbed and ionised, and a mass spectrum is recorded along with its current position. This enables plotting images that show the spatial distribution and abundance of a selected $\mathrm{m} / \mathrm{z}$ species, and therefore molecule, in the sample. To do so, the intensity values of a selected $\mathrm{m} / \mathrm{z}$ species (or $\mathrm{m} / \mathrm{z}$ interval) are extracted from each acquired mass spectrum and then arranged into an image based on the original positions of the respective mass spectra (Fig. 1a and b). After the measurement, an optical image of the very same sample can be taken and coregistered with the MSI data (Fig. 1a and c).

The ability to combine MSI data with histological and morphological information is critical for biomedical research. ${ }^{9}$ This allows not only a view of molecular distributions in their histological context, but also the use of the histological information to define regions-of-interest (virtual micro-dissection)
Maastricht MultiModal Molecular Imaging (M4I) institute, Division of Imaging Mass Spectrometry, Maastricht University, Universiteitssingel 50, 6229 ER Maastricht,

The Netherlands. E-mail: t.porta@maastrichtuniversity.nl,

b.balluff@maastrichtuniversity.nl

$\dagger$ These authors contributed equally to this work. 
a)

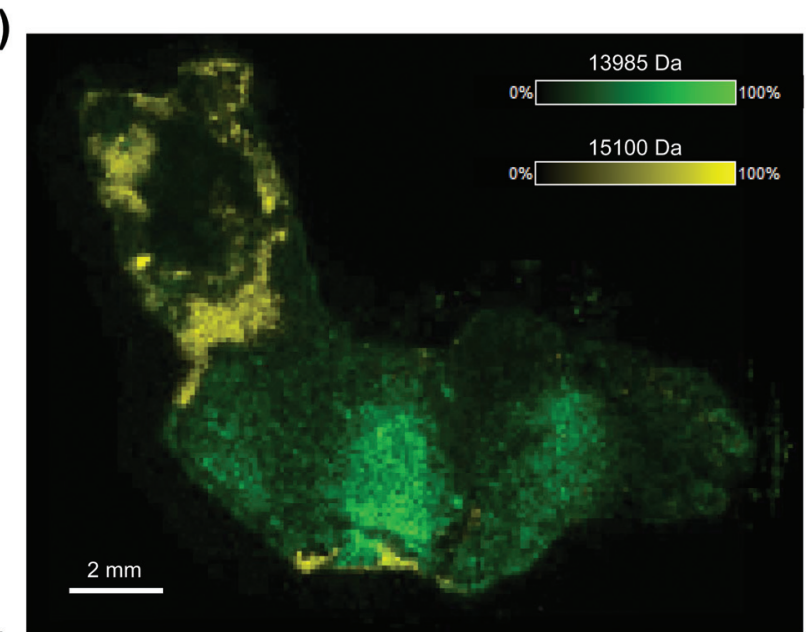

c)

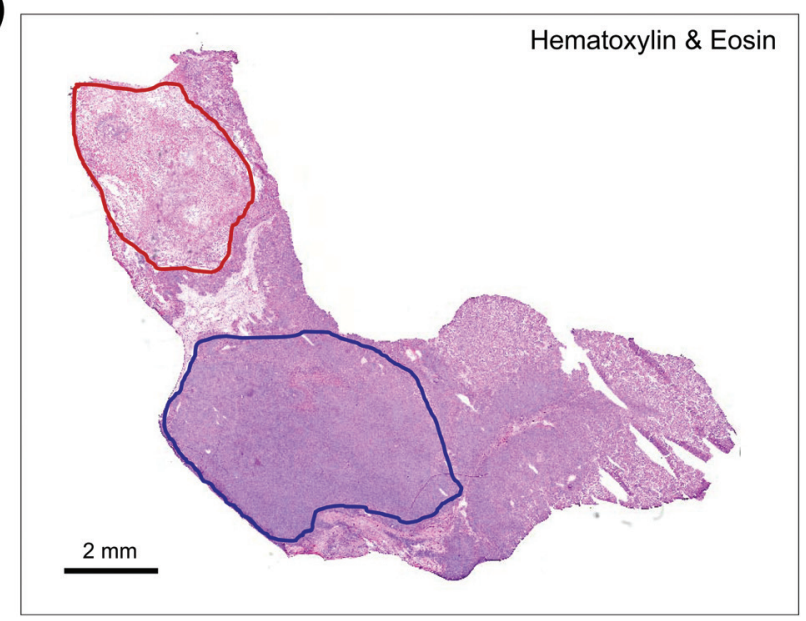

b)

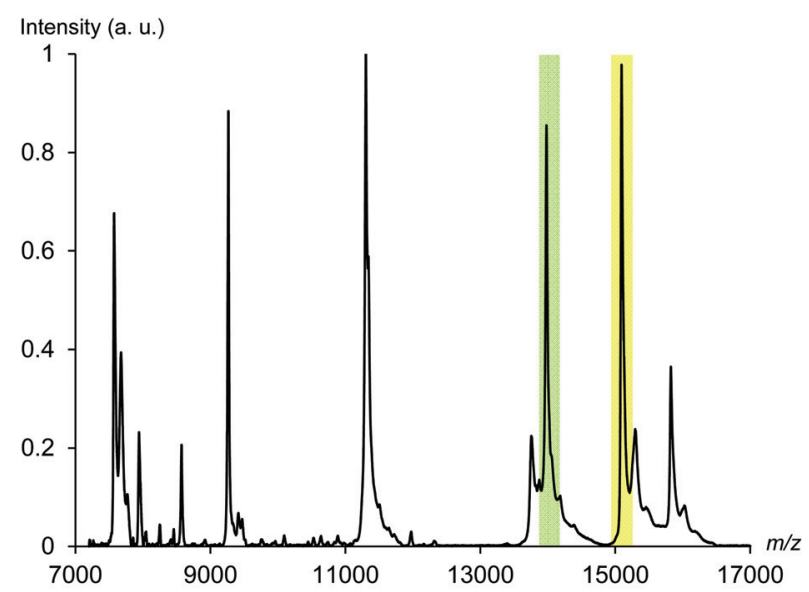

d)

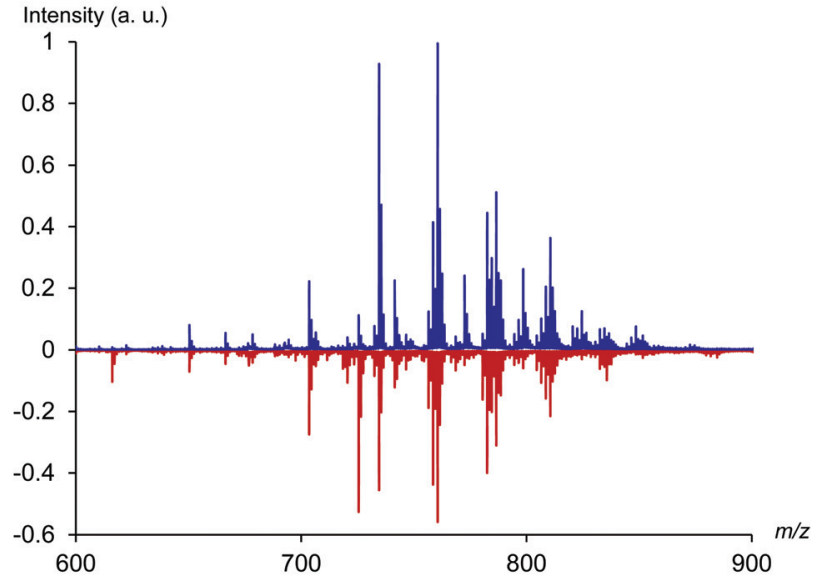

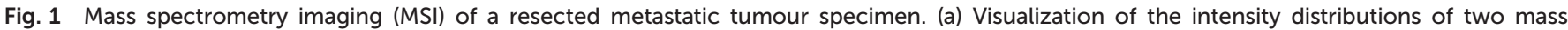

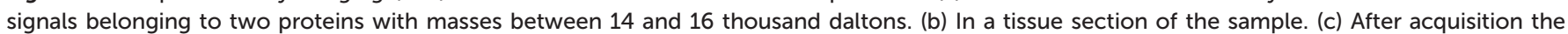

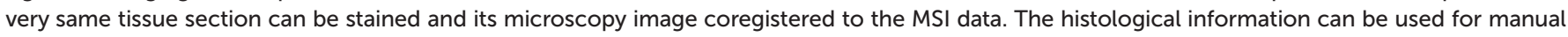

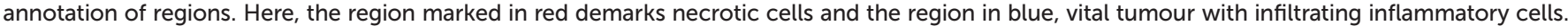

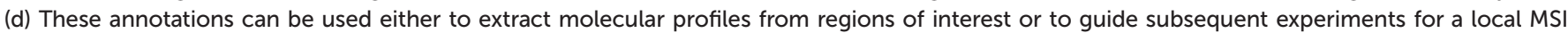
analysis or liquid extraction.

that harbour the cells of interest in order to extract their characteristic profiles from different molecular classes such as metabolites and proteins (Fig. 1c and d). ${ }^{10}$

These cell-type specific molecular profiles increase the specificity of the investigation, making MSI an attractive tool in clinical research. This is especially true of cancer research, where MSI has made most of its contributions to biomarker discovery, description of inter- and intratumor heterogeneity, and high-throughput profiling to complement established histopathological diagnostics. ${ }^{11}$ The latter has especially benefited from the rise of ambient ionization methods, which usually do not require sample preparation, and accelerated MSI instrumentation. ${ }^{12}$ Both innovations now enable the analysis of samples at time scales that could be compatible with clinical practice. Furthermore, protocols have been developed to make MSI compatible with routine clinical tissue processing, such as formalin-fixed, paraffin-embedded specimens. ${ }^{13,14}$ Thus, MSI is not only considered a powerful bio- medical research tool, but also has the potential to become a clinical assay itself.

In this article, we review the history of MSI in biomedical research in the light of the continuous technical developments and improvements over the last 10 years, which were stimulated by biomedical research and clinical needs. Existing limitations of MSI will be discussed, which will highlight the efforts that the MSI community must undertake to drive this technology further, especially for clinical research and related applications.

\section{MSI imaging techniques}

Mass spectrometry imaging (MSI) was developed in the early 1960 s with the introduction of secondary ion mass spectrometry (SIMS). ${ }^{15}$ In SIMS, a pulsed ion beam moves across the sample's surface, and due to its impact, secondary ions are 
generated locally and then directed to the mass spectrometer inlet (Fig. 2a). This technique has been used for imaging the elemental and molecular composition of surfaces at spatial resolutions in the subcellular scale (Fig. 2d). ${ }^{16}$

It was not until the mid- and late 1990s that MSI based on matrix-assisted laser desorption/ionization (MALDI; Fig. 1b) was applied to biological tissue sections, which are placed as sections on target plates ${ }^{17}$ or, a few years later, on (conductive) glass slides. ${ }^{18}$ Using MALDI as a soft ionization technique, it became feasible for the first time to image the distribution of larger biomolecules in tissues (Fig. 2e). ${ }^{17,19}$ Therefore, most commercial MALDI-MSI systems use a time-of-flight mass analyser.

In contrast to SIMS, MALDI uses a laser to probe a specific location on a tissue's surface (Fig. 2b). MALDI-MSI requires the application of an organic matrix to act as a mediator between the laser energy and the analytes and to promote their ionization. For a successful MALDI imaging experiment, homogeneous matrix deposition across the tissue's surface is crucial, and can be accomplished by spraying, spotting, or sublimation. While this was done initially by hand-held sprayers, biomedical research questions quickly demanded the reduction of variance-within and between samples-through automation of the matrix deposition. Several commercial systems are now available (e.g. Bruker ImagePrep, SunChrome SunCollect, HTX TM-Sprayer, tardo iMatrixSpray, TransMIT SMALDIPrep), which differ in their condition control (temperature, oxygen level), homogeneity of the matrix coating, and average matrix crystal size, all of which determine the experimental limitations. ${ }^{20}$ The matrix crystal size, for instance, defines the achievable spatial resolution, ${ }^{21}$ and environmental conditions together with the chosen matrix and solvent influence the extraction capabilities and therefore the molecular class that can be investigated.

Proteins were the first molecular class to be visualized by MALDI-MSI. ${ }^{17}$ By the use of other matrices and sample prepa- a)

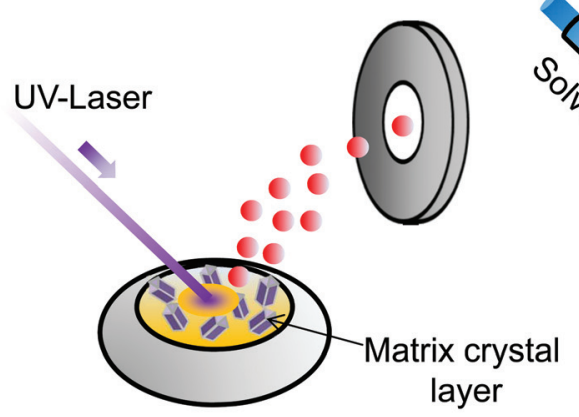

b)

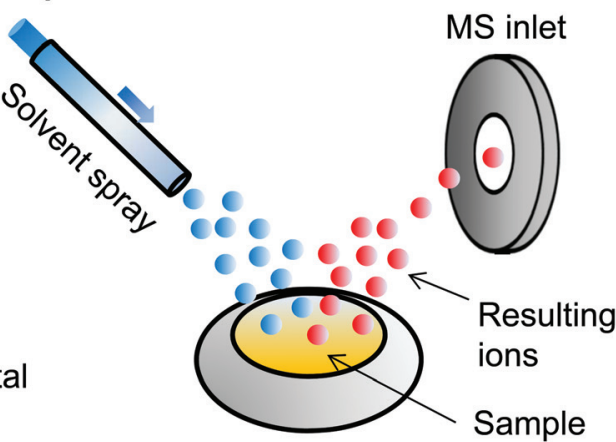

e)

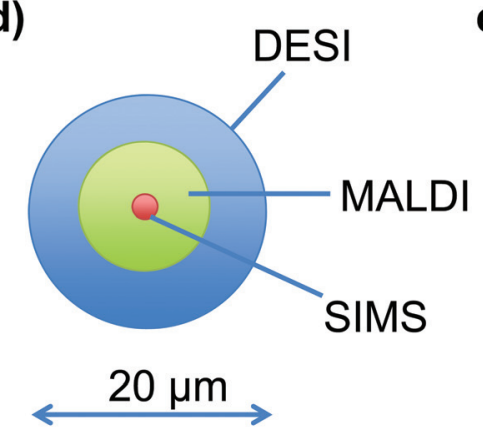

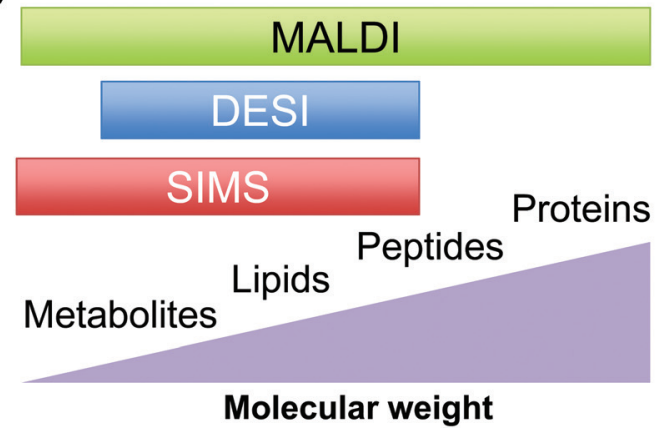

c)

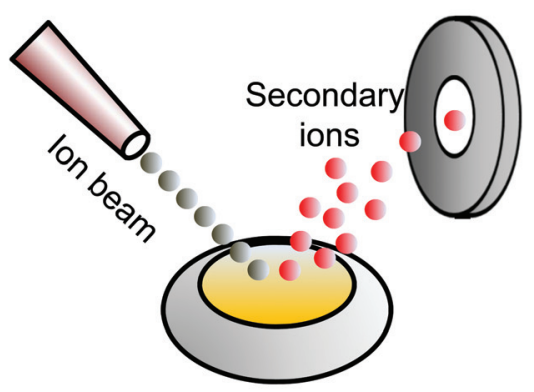

f)

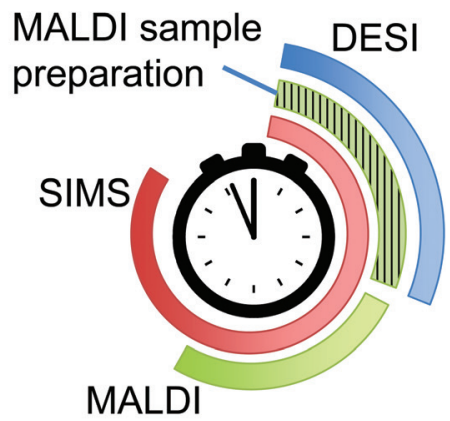

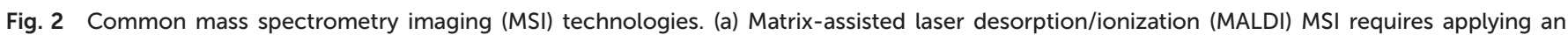

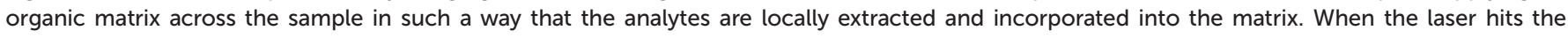

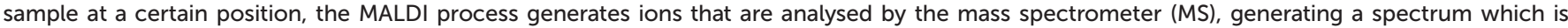

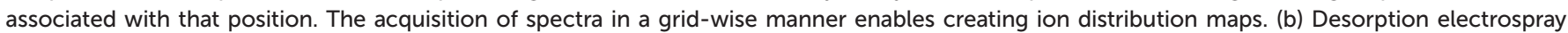

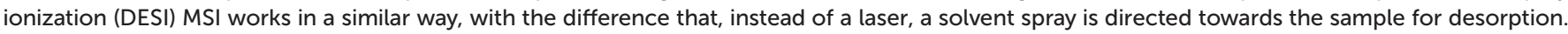

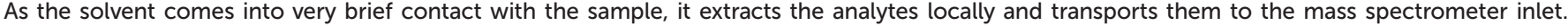

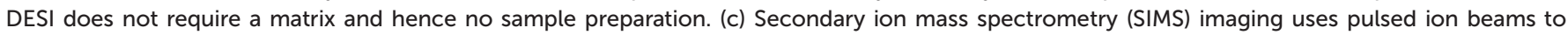

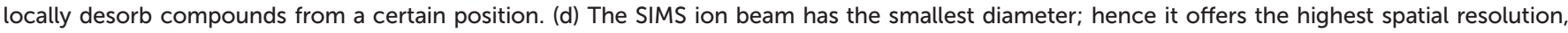

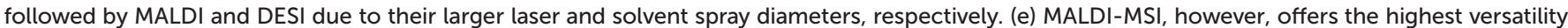

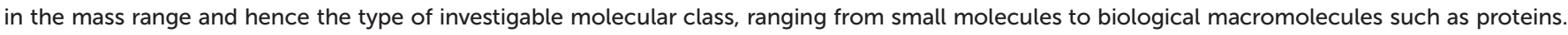

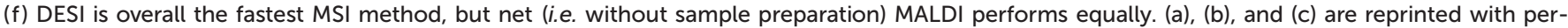
mission from Addie et al. ${ }^{252}$ Copyright (2015) American Chemical Society. 
ration, MALDI-MSI has been quickly extended to other molecular classes such as peptides, lipids, and small molecules including exogenous compounds like drugs (Fig. 2e). ${ }^{22}$ For each of these molecular classes, specific sample preparation protocols have been optimized to improve their detection. These optimizations include solvent washes and recrystallization for low abundance intact proteins, ${ }^{23}$ enzymatic on-tissue digestion for peptide imaging, ${ }^{24}$ and in situ derivatization of analytes in order to increase their ionization efficiency. ${ }^{25}$ Due to its versatility in terms of spatial resolution and molecular coverage, MALDI-MSI has become the most popular MSI technique over the past few years and has been successfully used in many clinical research studies, of which the most important examples will be presented below. However, MALDI-MSI suffers from a chemically intensive sample preparation, which is time consuming and can be a source of artefacts. ${ }^{26,27}$ This drawback has led to the development of other imaging-compatible ionization techniques.

Desorption electrospray ionization (DESI) is one of the first ionization sources to allow imaging under ambient conditions. ${ }^{28}$ In DESI, a solvent of charged droplets is directed toward the surface, which first leads to desorption of the analytes followed by their ionization based on the same principle as electrospray ionization (Fig. 2c). Similar to the laser in MALDI-MSI, the spatial resolution of a DESI-MSI experiment is partly determined by the diameter of the aerosol hitting the surface of the sample (Fig. 2d). As the spray is applied continuously and the sample stage moves continuously, the horizontal pixel size is defined by the analyser scan time during which the sample stage moves a certain distance. ${ }^{29}$ With the introduction of high-repetition rate lasers, a quasi-continuous situation is attained which significantly improved MALDI-MSI acquisition speed. The horizontal pixel size is defined by the stage motion, laser frequency, and a parameter defining the laser shots to be averaged per pixel. ${ }^{30}$ In both cases, the distance between two horizontal line scans determines the vertical pixel size.

With respect to the molecular classes that can be investigated, DESI-MSI experiments from tissues have been mainly reported on small molecules such as metabolites (e.g. neurotransmitters), drugs, and lipids (Fig. 2e). ${ }^{31-33}$ While changing the spray solvent composition can selectively promote the detection of certain molecules, the spray solvent can also be loaded with a derivatization agent. ${ }^{34}$ In this so-called "reactiveDESI" set-up, while the charged droplets hit the surface, a short and selective chemical reaction can take place between the derivative agent and the target analytes to improve their detection. The ability to study samples with minimal or no sample preparation makes DESI-MSI a valuable tool for highthroughput MSI and therefore especially interesting for large sample cohorts encountered in clinical research (Fig. 2f). ${ }^{35}$

DESI has paved the way for a variety of other kinds of ambient ionization techniques. However, their current impact regarding clinical research is at present limited, as they are focused on their technical development or have been recently introduced into the field.
Nano-DESI (nanospray desorption electrospray ionization), for instance, improves DESI by substituting the charged aerosol with a continuous micro-extraction realized by a liquid bridge of solvent between two capillaries, leading to higher spatial resolutions of up to $12 \mu \mathrm{m}$ (ref. 36) and the capability of protein analysis. ${ }^{37}$ LESA (liquid extraction surface analysis) was reported for studying distributions of a wide range of analytes, including proteins, at the millimetre scale. LESA relies on the formation of a liquid micro-junction with the tissue and allows static extraction of analytes. ${ }^{38,39}$ LAESI (laser-ablation electrospray ionization) combines a mid-infrared laser for desorption and an orthogonal electrospray for transferring multiple charges to the analytes. This promises to extract larger biomolecules such as peptides and small proteins with subsequent MS/MS identification in a single run. ${ }^{40}$ Finally, the matrix-free laser methods LA-ICP (laser-ablation inductivelycoupled plasma), which enables analysing elemental distribution in samples, ${ }^{41}$ and NIMS (nanostructure initiator mass spectrometry), ${ }^{42}$ another matrix-free soft-ionization technique, are also worth mentioning.

The three main techniques MALDI, DESI, and SIMS are compared in Fig. 2 according to their working principle, achievable spatial resolution, molecular coverage, and experimental time investment, all of which are important for biomedical research studies.

\section{Latest technical developments in MS imaging}

\section{The quest for high throughput}

Clinical research usually implies the analysis of hundreds of patient samples, representative of large clinical cohorts. To address clinical questions at relevant time scales, recent developments have enabled high throughput analysis with unprecedented data acquisition speeds. ${ }^{43}$

While most MALDI-TOF instruments use a spot-by-spot sampling technique in which the stage moves in discrete steps under a stationary laser, recently developed systems utilize continuous laser raster sampling to acquire data while continually firing the laser and scanning the stage. ${ }^{44,45}$ The performance is further improved by faster laser repetition rates, improving the acquisition rate to 50 pixels per second (50 times faster than that available in 2006) (Fig. 3a). ${ }^{46,47}$

To illustrate, if one wants to image a surface area of $10 \times$ $10 \mathrm{~mm}$ at a spatial resolution of $50 \mu \mathrm{m}$ (i.e. with a pixel size of $50 \times 50 \mu \mathrm{m}$, which is a total of 40000 pixels), it would almost take six hours using instruments operating at an acquisition speed of two pixels per second. On the other hand, the same experiment performed at an acquisition speed of 50 pixels per second would only take 13 minutes.

Spraggins et al. obtained the distribution of lipids in a sagittal rat brain tissue section within 10 minutes, obtained from high speed MALDI-TOF MSI experiments combining a high sample stage velocity of $5 \mathrm{~mm} \mathrm{~s}^{-1}$ in continuous laser raster mode with a high laser repetition rate of $3 \mathrm{kHz} .{ }^{30}$ Using 
a)

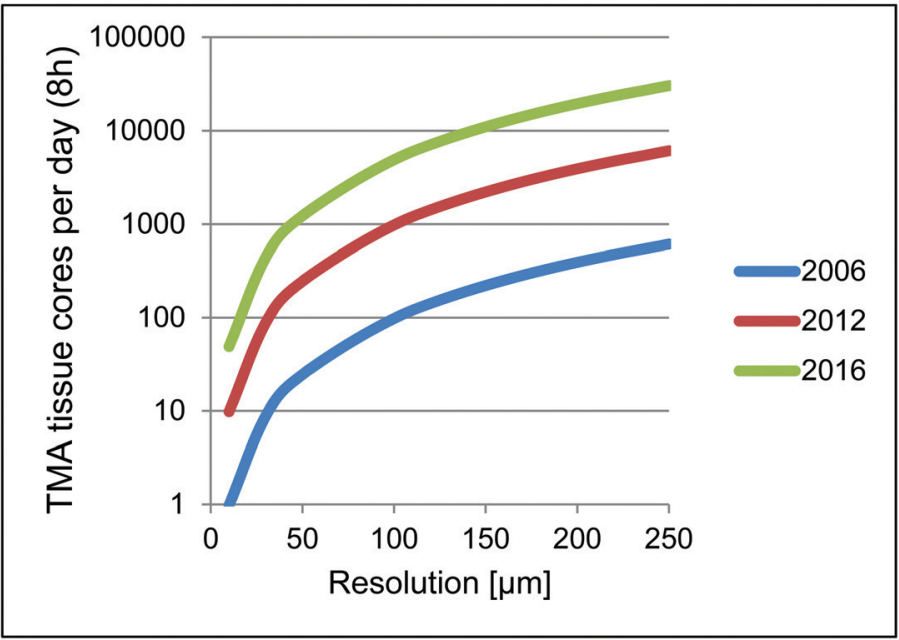

b)

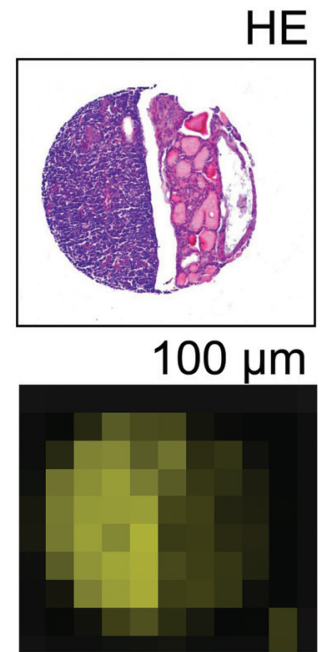

$50 \mu \mathrm{m}$

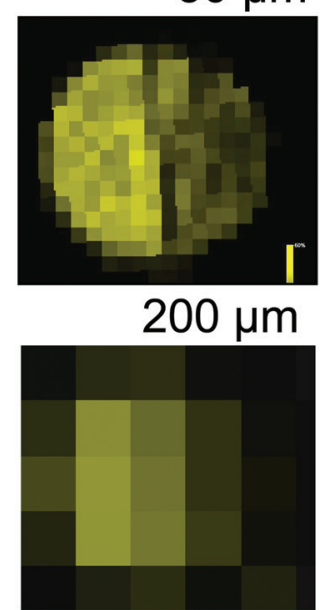

C)
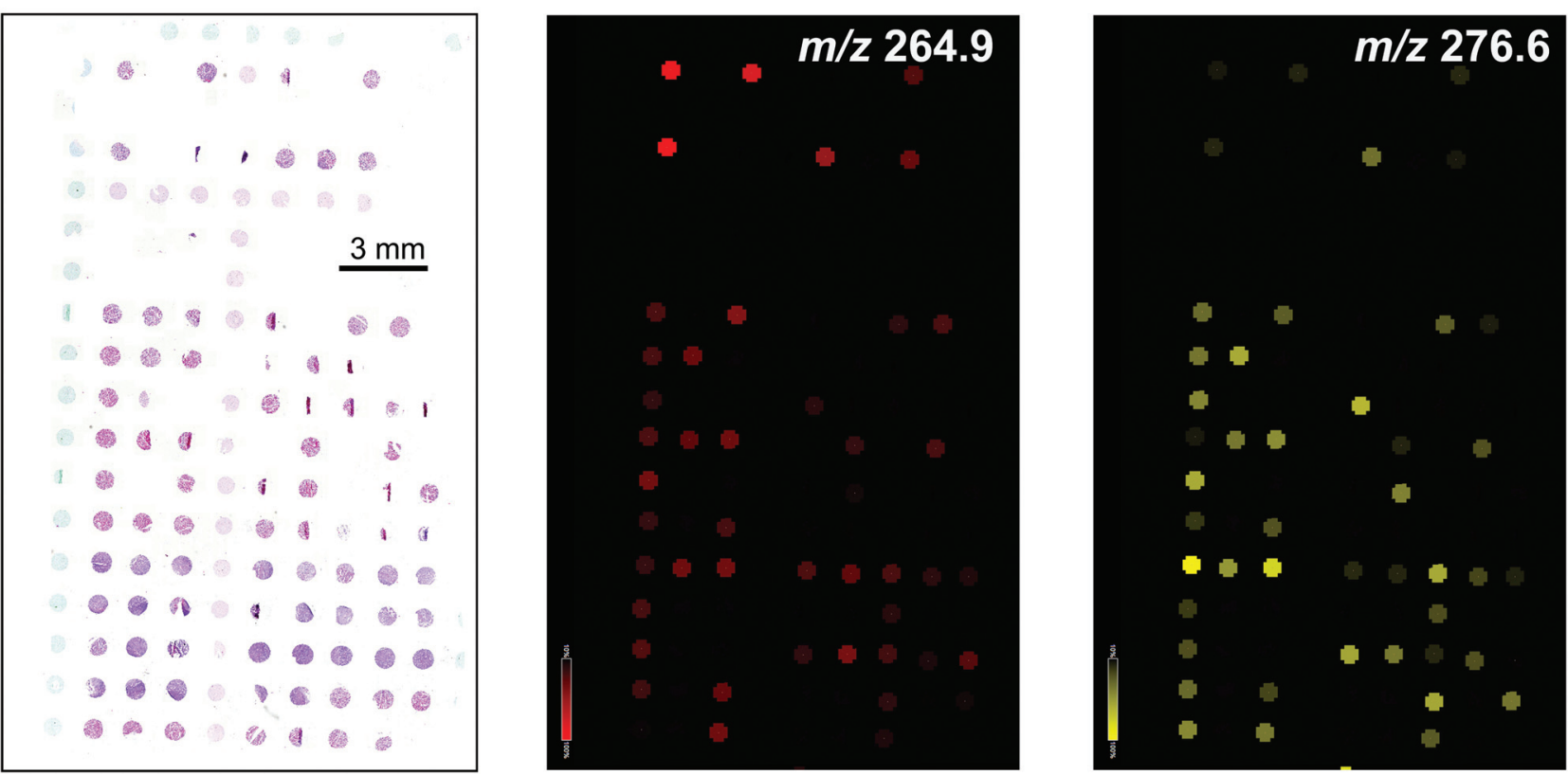

Fig. 3 High-throughput character of MSI. (a) Technical developments in the last ten years have sped-up MSI systems by one and a half orders of magnitude, as shown here for the number of analysable tissue cores per eight hours as a function of spatial resolution. (b) Tissue cores are punchouts from bigger tissue samples (usually formalin-fixed paraffin-embedded tissue blocks) with a diameter of 0.5 to $2 \mathrm{~mm}$. As can be seen in the depicted example (scale bar $=400 \mu \mathrm{m}$ ), high resolution scanning is recommended (i.e. here around $50 \mu \mathrm{m}$ ) to distinguish histological details within a tissue core. (c) The experimental throughput can be increased by analysing a tissue microarray (TMA) which can contain hundreds of tissue cores i.e. hundreds of patients - on one microscopy glass slide $(75 \times 25 \mathrm{~mm})$, as shown in the left panel. This allows correlating differential patterns of molecular species within the clinical data of the patient tissue cores present on the TMA. Examples of visualization of two small molecules are shown in the middle and right panels. Abbreviations used: H\&E, haematoxylin and eosin staining.

MS/MS, Prentice et al. were able to image drugs and common kidney lipids in a complete section in less than 20 minutes at a spatial resolution of $100 \mu \mathrm{m} .{ }^{47}$ With this next-generation of high-speed MALDI-TOF MSI systems, it is now even possible to use volatile matrices, which can improve the sensitivity for certain molecular classes compared to commonly used matrices. ${ }^{44}$ Combined with the use of tissue microarrays, which can concentrate dozens to hundreds of patient biopsies on one glass slide, a throughput of thousands of patients in a few days has now become feasible (Fig. 3a and c). ${ }^{48}$

Although major improvements reported so far are related to MALDI-MSI, recent developments have put DESI-MSI in a competitive position with respect to speed, with acquisition speed capabilities of 30 pixels per second. ${ }^{49}$ In addition, the absence of time-consuming sample preparation contributes considerably to reducing the overall analysis time (Fig. 2f). 
Altogether, these improvements offer the possibility of answering clinical questions in short timeframes at high spatial resolution.

\section{Imaging at cellular length scales}

Tissue is a highly complex system at the cellular level. ${ }^{50}$ Highresolution imaging combined with molecular specificity would thus be extraordinarily beneficial for a better understanding of the construction of a cellular system, especially in small-scale samples such as biopsies or tissue microarrays cores (Fig. 3b). Developments in sampling techniques have enabled imaging at cellular length scales. ${ }^{51}$ In cancer, for instance, this allows for a more differentiated molecular analysis by separating tumour cells from stromal components ${ }^{52}$ or inflammatory infiltrates. ${ }^{53}$

In this sense, SIMS is particularly attractive for sub-micrometre resolution imaging, ${ }^{54}$ but at the expense of long acquisition times. Advances in ion probe technologies have increased the dynamic range and sensitivity of SIMS, allowing 2- and 3-dimensional localization of analytes in a variety of cells. $^{55,56}$ In 2011, Brison et al. used SIMS to create molecular depth profiles of human HeLa cells treated with the anticancer drug bromodeoxyuridine allowing imaging of molecular and atomic species from BrdU inside the nuclei of the cells. ${ }^{57}$

While current commercial MALDI-MSI instrumentation allows the acquisition of $10 \mu \mathrm{m}$ pixels, $5 \mu \mathrm{m}$ MALDI imaging without oversampling has recently been reported. ${ }^{58}$ MALDI sources operating at atmospheric pressure allow for the return of subcellular pixel sizes below $2 \mu \mathrm{m} .{ }^{59,60}$ This is possible by focusing the laser beam, which consists of a pre-focusing part outside a vacuum and a final focusing part within the vacuum directly above the sample manipulator. ${ }^{59,60}$ However, decreasing the size of the sampled area affects the sensitivity negatively and there is a compromise to make between resolution and sensitivity. ${ }^{61}$

Laser-ablation inductively coupled plasma mass spectrometry (LA-ICP-MS) offers nowadays a lateral resolution down to $1 \mu \mathrm{m}$ and has been applied in biomedical research such as epitope-based MSI. ${ }^{41}$

\section{Epitope-based MSI}

Targeted epitope-based MSI utilizes laser cleavable mass tags bound to specific antibodies for detecting multiple antigens in a single tissue section. ${ }^{62}$ Imaging mass cytometry, based on LA-ICP-MS, has emerged as a highly multiplexed epitopebased imaging approach that uses rare earth metals as reporters on antibodies enabling high-dimensional, single-cell imaging of the cell type and state. ${ }^{63}$ Bodenmiller et al. demonstrated the simultaneous imaging of 32 proteins and protein modifications at subcellular resolution in human breast cancer samples, allowing delineation of cell subpopulations and cell-cell interactions and highlighting tumour heterogeneity. ${ }^{64}$ The advantage of this approach compared to untargeted MSI is its increased sensitivity and specificity at the price of being able to target antigenic proteins alone.

\section{Advances in sample preparation}

MSI experiments have benefited from technical advancements at the MS instrumentation level. However, sample preparation is equally important, and therefore techniques and protocols have also been improved to match the capabilities of new MS instrumentation. It has been shown that optimized sample washing protocols can significantly improve the overall spectral quality of certain molecular classes such as lipids or proteins. ${ }^{65-69}$ Furthermore, in MALDI-MSI, new matrix deposition techniques that provide smaller crystal sizes and decreased diffusion were necessary to match the reduced laser focus. Today, new matrix coating systems, such as sublimation devices, offer crystal sizes of less than $3 \mu \mathrm{m} .^{23,70}$ Also, precoated glass slides were introduced that decrease sample preparation times and batch effects due to temporally very distant matrix coating procedures. ${ }^{71}$ Sample preparation protocols were further developed to enable the detection of previously unexploited molecular information.

Sample preparation can be specifically optimized by the use of on-tissue derivatization agents. For target analytes such as drugs, derivatization can be extremely useful to increase their ionization efficiency and/or to avoid background interferences by shifting their $\mathrm{m} / \mathrm{z}$ signal in the spectrum. Barre et al., for example, used GirT to derivatize triamcinolone acetonide, a drug employed to ameliorate the inflammation and pain of osteoarthritis. $^{72}$ Recently, Liu et al. used diethyldithiocarbamate to enhance the signal of platinum-based drugs, which are widely used anti-cancer agents. ${ }^{73}$ But derivatization can also be beneficial to enhance the signal of a group of molecules of interest. Esteve et al. used three derivatives to enable imaging of 23 amino metabolite distributions such as glutamate or GABA in mouse brains. ${ }^{25}$ Franck et al. have improved on-tissue protein identification by derivatizing $\mathrm{N}$-terminal peptides, which increased fragmentation yields significantly. ${ }^{74}$ Finally, the spray solvent of reactive DESI-MSI was loaded with a derivatization agent to promote a selective and short chemical reaction for signal enhancement of cholesterol in brain tissue. ${ }^{75}$

Another important on-tissue chemistry is digestion, in which an enzyme is deposited onto the tissue's surface. In situ proteolytic digestion is key in the proteomic analysis of formalin-fixed paraffin-embedded (FFPE) tissues, which constitute the vast majority of archived tissues in a clinical setting. The development of methods for the reversal of the formalin-fixation in order to maximize the obtainable proteomic information has hence been of interest to many MSI groups with clinical aspirations. $^{76-78}$ These different approaches have been further investigated, compared, and optimized in terms of data quality, tissue-type specific dynamics, and reproducibility. ${ }^{79-82}$ The use of enzymes is not only restricted to the aim of detecting peptides, but also specific post-translational modifications. Glycosylation is one of the most important protein modifications involved in cell signalling and recognition. The use of PNGase $\mathrm{F}$ to gain access to glycans has been transferred to MSI of frozen and FFPE tissues and shown to reveal biomedically relevant information. ${ }^{83,84}$ First, Holst et al. combined derivatiza- 
tion and subsequent PNGase digestion to distinguish the distribution of glycan enantiomers in sarcoma tissues. ${ }^{85}$ Shortly later, Heijs et al. sequentially applied different enzymes on the very same FFPE tissue section to obtain information on both $N$-glycans and peptides. ${ }^{86}$

These approaches show that the molecular information contained in FFPE tissues on proteomic and protein-modification levels is rich and can be extracted using appropriate techniques. Recently, Walch et al. demonstrated that metabolic information can also be extracted from clinical FFPE tissues using high-mass resolution MSI. ${ }^{14}$ Running against the assumption that metabolites are washed out during tissue fixation, many metabolites with clinical value are retained. ${ }^{87}$

\section{Advances in mass resolution, accuracy, and selectivity}

MSI has not only advanced in terms of speed, spatial resolution, and sample preparation, but has also profited from general improvements in mass analyser technologies in order to increase mass resolution and mass accuracy.

Time-of-flight. Most MALDI-MSI instruments are still based on time-of-flight (TOF) mass spectrometry (MS). TOF-MS offers a high mass range and high throughput, and the latest developments have contributed to increasing its performance in terms of mass resolving power and mass accuracy. Particularly, the introduction of orthogonal acceleration geometry (oa-TOF) allows for hybridization between TOF and quadrupole mass analysers, i.e. QqTOF have been demonstrated to be particularly suited to the analysis of small molecules, with mass resolving power up to 50000 and with MS/MS ability. ${ }^{88-90} \mathrm{TOF} / \mathrm{TOF}$ instrumentation that enables multiple fragmentation events to be performed in a single laser shot was also demonstrated to be beneficial for the on-tissue quantitation of drugs. ${ }^{91}$

Fourier-transform ion cyclotron resonance mass analysers. Fourier-transform ion cyclotron resonance mass spectrometry (FT-ICR MS) provides the highest mass resolving power $(\gg 100000)$ and accuracy $(<1 \mathrm{ppm})$ and allows for multistage MS/MS capabilities. ${ }^{92}$ FT-ICR MS is not routinely used for high throughput/resolution imaging due to the long in-cell accumulation required. But the use of FT-ICR MS for high mass resolution MS imaging has enabled imaging of mass channels with a bin size as low as $\Delta m / z=0.005$, thereby revealing new features that cannot be resolved with lower resolution instrumentation. ${ }^{92-95}$ The increased mass accuracy provided by FT-ICR MS has also improved identification capabilities in MSI (see the section on identification strategies below).

Tandem mass spectrometry. Tandem mass spectrometry provides additional information on the structure of the analysed molecules based on detecting their fragments. In MSI, tandem MS has been performed directly from tissue to identify peptides or lipids using either TOF/TOF, Q-TOF, or Orbitrap systems. ${ }^{60,96,97}$ Tandem MS is also particularly suited for targeted imaging and offers unique capabilities in monitoring specific ion fragment transition(s) ("selected reaction monitoring", SRM) which provides unprecedented selectivity and therefore sensitivity for given compounds. Despite their lower mass resolution, quadrupole and ion trap mass analysers are particularly suited for targeted imaging of small molecules. ${ }^{31,98}$ Hence, especially drug imaging studies have benefitted from the high selectivity and speed of SRM imaging on MALDI and DESI systems..$^{29,99-101}$ But recently also parallel MS1 and MS2 have been introduced for SIMS. ${ }^{102}$

Ion mobility. The implementation of a post-sampling and post-ionization gas-phase separation technique in an MS imaging workflow is advantageous to differentiate isobaric analytes based on their different structures and also to discriminate between ions of interest and interfering biological matrix ions. ${ }^{103}$ The interest in ion mobility separation (IMS) in MSI has therefore increased considerably over the last few years. ${ }^{104}$ IMS has proved suitable for the analysis of various analytes, from small drugs,${ }^{105}$ carbohydrates, and lipids ${ }^{106-108}$ to peptides, ${ }^{109,110}$ proteins, ${ }^{111,112}$ and protein complexes. ${ }^{113}$ In MALDI-MSI, IMS helped spatially localize and structurally identify acylcarnitines and a variety of lipid species present in breast tumour xenograft models. ${ }^{106}$ In DESI, ion mobility demonstrated its use in studying fragile species like gangliosides, thereby generating complementary information to MALDI-MSI. ${ }^{107}$ Recently, FAIMS (field asymmetric waveform ion mobility) has been introduced and coupled with DESI-MSI; it has been demonstrated to increase the sensitivity and signal to noise of gangliosides and cardiolipins. ${ }^{114}$

\section{Identification strategies for metabolites, peptides, and proteins}

The technical advances mentioned in the section before, especially the availability of high mass resolution and additional separation techniques such as IMS, have also helped improve the ability to determine the identity (ID) of detected $m / z$ species. This is of key importance in MS imaging when investigating potential new biomarkers, understanding the biology and chemistry of a diseased system, or confirming the identity of targeted compounds. In MSI, the identification of certain compounds is either performed by MS/MS experiments directly from tissue and/or by matching the measured $\mathrm{m} / \mathrm{z}$ value to a database. On-tissue procedures face the challenge of a small amount of analytes present in an imaging pixel (in a $50 \mu \mathrm{m}$ pixel there are about 25 cells). Ionization procedures that could increase the ion yield per pixel would be valuable. Using a second laser to initiate a second ionization wave in the gas phase, Soltwisch et al. increased ion yields by up to two orders of magnitude. ${ }^{115}$ But this has been restricted to lipids so far. The database approach makes use of either public databases (e.g. METLIN or MSiMass list) or private databases based on a set of compounds which have been previously determined to be present in that sample by separate proteomics/metabolomics experiments from tissue extracts. ${ }^{116}$ Overall, there are different identification procedures, which depend on the compounds of interest:

Intact proteins. The majority of intact protein MSI experiments are performed on linear time-of-flight (TOF) mass analysers, which do not return structural information for direct on-tissue identification. Consequently, one way of identifying proteins has therefore been to first extract all protein content 
from the tissue, and then separate the proteins by HPLC fractionation, and perform either top-down or bottom-up analysis on the purified fractions containing the masses of interest. ${ }^{117,118}$ Also, while TOF-MS offers the benefits of a wide mass range and high throughput, it falls short in mass resolution in the higher mass range. FT-MS provides a significantly higher mass accuracy than TOF analysers. Spraggins et al. have used FT-ICR MS to image proteins up to $12 \mathrm{kDa}$ and enable their identification based on correlating the accurate protein signals $(<5 \mathrm{ppm})$ with top-down proteomics data. ${ }^{119}$ The results of such experiments are very valuable input for public protein MSI databases, such as the MSiMass list. ${ }^{120}$

Peptides. The database lookup approach can be applied to peptides as well, where highly accurate masses can be correlated to the results of parallel bottom-up proteomics experiments. ${ }^{78}$ This must, however, involve on-tissue digestion in the MSI sample preparation. Heijs et al. have optimized the use of several MALDI-compatible proteases, which enabled assignment of 630 peptides, corresponding to 280 proteins, to peaks found in the FT-MSI data sets. ${ }^{78}$ In the mass matching approach, the confidence in identification is directly dependent on the mass accuracy of the MSI experiment. Schober et al. have determined the necessary mass tolerance to be less than 3 ppm. ${ }^{121}$ But in contrast to proteins, peptides can also be identified directly from tissue by using MS/MS experiments. The use of TOF/TOF analysers for on-tissue identification has also been demonstrated, where the first TOF is used to select a precursor ion for fragmentation and the second TOF is used for the rapid and parallel analysis of fragments allowing the identification of the isolated compound of interest. ${ }^{122-124}$ The identification from tissue is challenging due to the lack of chromatographic separation in an imaging experiment. Adding an additional separation step after surface sampling, either based on gas-phase ion mobility or liquid-phase chromatography (LC), can provide improved selectivity and hence confidence in analyte identification. To illustrate, LESA-MS combined with bottom-up proteomics provides a way to increase the number of identifications to around 500 proteins, but comes at the price of lower spatial resolution. ${ }^{38}$

Small metabolites and lipids. Due to a lack of comprehensive MALDI and DESI MS/MS databases and search algorithms for lipids and small metabolites, high mass accuracy provides an important indication of identity. A common approach is to first match the measured molecular weight with a small mass tolerance to a public database, such as HMDB (http://www. hmdb.ca/), METLIN (https://metlin.scripps.edu), or lipid maps (http://www.lipidmaps.org/), and then check if the observed fragmentation spectra are in line with the structure of the proposed match. ${ }^{125}$ The final confirmation can be obtained by comparing the fragmentation pattern with the one from a corresponding standard compound. ${ }^{87}$

\section{Three-dimensional MSI}

The reconstruction of analyte abundances in an entire threedimensional (3D) volume allows delivering contextual information to $2 \mathrm{D}$ images and reducing the possibility of neglecting small anatomical structures. 3D MSI data can be created in two ways: (i) by the sequential acquisition and registration of multiple $2 \mathrm{D}$ tissue sections followed by combination into a single 3D representation achievable with MALDI $^{126-128}$ or DESI, ${ }^{129}$ or (ii) by depth profiling using secondary ion mass spectrometry. ${ }^{130-134}$

For the first approach, accurate coregistration of a stack of consecutive 2D MSI images is the most critical and difficult step. In addition, comparison with other modalities (e.g. $\mathrm{MRI}^{135}$ ) can be required. Chughtai et al. have developed a coregistration technique which consists of using fiducial markers with optical and molecular properties. These markers allowed, on the one hand, accurate coregistration of multimodal data from MSI with histological and fluorescent microscopy images. On the other hand it also allowed coregistering a set of serial tissue sections to reconstruct 3D MSI images of a breast cancer sample. ${ }^{136}$ Also, recently, Patterson et al. described how open-source software can be used to obtain high-quality visualizations and multivariate segmentations from 3D MSI data. ${ }^{137}$ By analysing atherosclerotic plaques, they also demonstrated the added value of 3D MSI for the investigation of samples where the volumetric spatial organization is important. Furthermore, 3D MSI has been used successfully in the field of microbiology to characterize microbial metabolic exchange $\mathrm{e}^{127}$ and also for 3D single cell imaging $^{126,130,134}$

\section{Advances in bioinformatics}

The success of a MSI study is strongly dependent on downstream data analysis capabilities. Clinical MSI usually involves the analysis of dozens to hundreds of samples to achieve the required statistical power. With the advent of high mass and high spatial resolution data sets and therefore individual data set sizes in the gigabyte range, the processing and handling of data in a clinical MSI study has become computationally demanding. While vendors are incorporating on-the-fly data reduction and processing methods during acquisition, software developers have come up with intuitive and efficient MSI software packages to facilitate the analysis of clinical MSI data. Commercial software packages, such as Multimaging (Imabiotech, France) or SCiLS (Bruker Daltonics, Germany), can handle terabyte-sized, multi-sample data sets and include many statistical tools for biomarker discovery. Open-source software is also available, such as MSiReader, ${ }^{138}$ Cardinal, ${ }^{139}$ Biomap, ${ }^{140}$ msiQuant, ${ }^{141}$ or SpectralAnalysis, ${ }^{142}$ but is less focused on the simultaneous analysis of several samples.

A special interest of researchers has also been to further develop data analysis techniques, which account for the very special nature of MSI data, i.e. multivariate data in a spatial context. Van de Plas et al., for example, correlated the multivariate patterns of a low resolution MSI image with the histological entities from a higher resolution optical image in order to create super-resolution MSI images at the resolution of the optical image. ${ }^{143}$ In this way they were able to increase the resolution of an MSI image by a factor of ten. Our group also exploited the spatial context of MSI data in another study. 
So far, classical statistical tests, such as a $t$-test, within a sample have not been valid due to the spatial dependence of the single spectra. We showed that using conditional autoregressive models, which account for the spatial autocorrelation of mass signals, within-sample statistical comparisons can be performed. This is useful, for example, in determining significant differences in drug distributions in a tissue. ${ }^{144}$

Clustering is a powerful tool in MSI and has been demonstrated to be capable of differentiating tumour types, visualizing intratumor heterogeneity, and segmenting anatomical structures. ${ }^{145}$ Also, clustering algorithms have been improved by incorporating the spatial information of the data. ${ }^{146}$

Likewise, the project MetaSpace uses the spatial information of the detected isotopic patterns to increase the confidence of metabolite identification. ${ }^{147}$ The MetaSpace project is an open-data repository where every active user can see the data of other users. The open design also enables the sharing of knowledge represented by manual annotations of molecules.

\section{Sharing data and knowledge}

Sharing data and knowledge is becoming more important, in general, in MSI. This is particularly critical for clinical MSI studies, where different scientific disciplines, represented by clinicians, biologists, chemists, and data analysts, have to work side by side. Therefore, platforms to share data and knowledge (and the capability of processing and analysing data together) are becoming vital for the success of projects.

Building blocks for these platforms are common standards and open data repositories. Introduced in 2012, imzML has become the de facto data exchange format in MSI, which is now also supported by most instrument vendors. ${ }^{148}$ Data repositories for MSI data followed, such as the open ProteomeXchange platform ${ }^{149}$ and MetaSpace, which allows online viewing of MSI data sets. ${ }^{147}$ The commercial SCiLS lab cloud (scils-cloud.de) goes a step further, allowing all collaborators including clinicians to contribute their knowledge on the same data online, similar in function to a Google document.

Other building blocks for sharing knowledge are common standards for reporting and guidelines for setting up and interpreting the results from clinical MSI experiments. Steps towards this have been taken by proposing guidelines for reporting MSI data and results based on the MIAPE (minimum information about a proteomics experiment) standard. ${ }^{150}$ Finally, Lou et al. have reported a comprehensive manual for a successful biomarker discovery in histologically complex tumour tissues. The aspects ranged from tissue preparation and data acquisition to data quality control, histology-defined data selection, data processing, and statistical analysis. ${ }^{151}$

\section{Highlights of clinical research performed with MSI}

Historically, clinical MSI was mainly represented by MALDI-MSI, orientated towards protein biomarker discovery, given the fact that results can be validated by existing techniques such as LC-MS/MS, SDS-PAGE, or immunohistochemistry. With the advent of ambient ionization methods, many studies have used DESI-MSI for clinical tissue classification based on lipid profiles. These two MSI-techniques have already proved useful to provide relevant information in several clinical research areas. Focusing on the accomplishments in oncology - which are summarized in Fig. 4 - this section will review major past and present highlights of clinical MSI, also in various other research areas such as neuropsychiatry and neurology, nephrology, ophthalmology, and finally rheumatology.

\section{MSI in oncology}

Biomarker discovery. Biomarker discovery has the aim of identifying patterns or single signals of biomolecules that can stratify patients according to their diagnosis, disease state (staging), and prognosis to enable a more personalized therapy. In 2003, Yanagisawa et al. were the first to report the successful use of MALDI-MS tissue profiling combined with class-prediction models based on differentially expressed proteins to accurately determine lung cancer histology, distinguish primary tumours from metastases, classify nodal involvement, and predict the prognosis of patients. ${ }^{118}$ This study was not an imaging study, but was an MSI landmark paper as it gave evidence of the potential of biomedically relevant information that can be obtained when interrogating tissue directly by MALDI-MS. The same group showed a few years later that MALDI-MS imaging was also able to obtain similar information from archived tissues where peptide profiles were found in 112 biopsies from lung-tumour patients to discriminate adenocarcinoma from squamous cell carcinoma. ${ }^{97}$ In the following years many oncological studies have exploited the potential of MSI to find biomarkers for diagnosis, prognosis, or therapy response prediction.

Diagnosis. Some of the first cancer MSI studies were interested in finding diagnostic markers, where the tumour profiles were compared to the healthy tissue correlate. One of the first studies in 2007 used MALDI-MSI to find the protein fragment Reg alpha as the potential biomarker for ovarian cancer, which has been confirmed in a second study by immunohistochemistry (IHC) on 179 tissue samples. ${ }^{152,153}$ In 2009, Cazares et al. found $\mathrm{m} / \mathrm{z} 4355$ to accurately discriminate cancer from uninvolved prostate tissue. The molecule was identified by ontissue MALDI tandem mass spectrometry as a fragment of mitogen-activated protein kinase/extracellular signal-regulated kinase kinase kinase 2 (MEKK2). The knowledge of the identity enabled investigating and confirming the discriminatory power of MEKK2 orthogonally by IHC. ${ }^{154}$

Classify preneoplastic lesions. The correct classification of preneoplastic lesions during screening or surveillance is crucial for initiating a curative treatment. For example, patients with intestinal metaplasia in the oesophagus are at higher risk of developing cancer. Elsner et al. have shown that the histological specificity of MSI provides a powerful tool to distinguish Barrett's adenocarcinoma from its premalignant stages based on several differentially expressed proteins. ${ }^{155}$ Another group at risk is patients with cirrhosis since they might develop liver cancer (HCC). Laouirem et al. investigated the mechanisms associated with the transition from cirrhosis 
a)

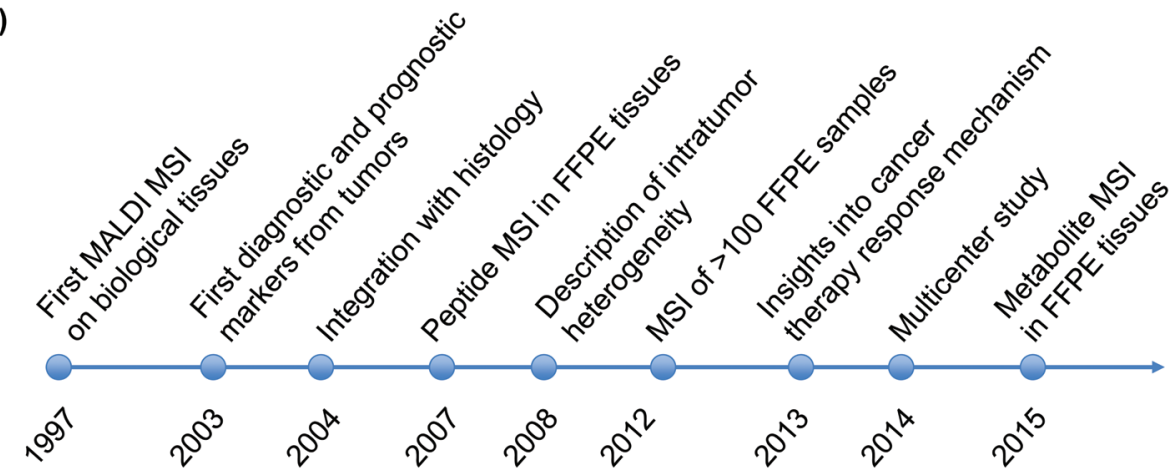

b)

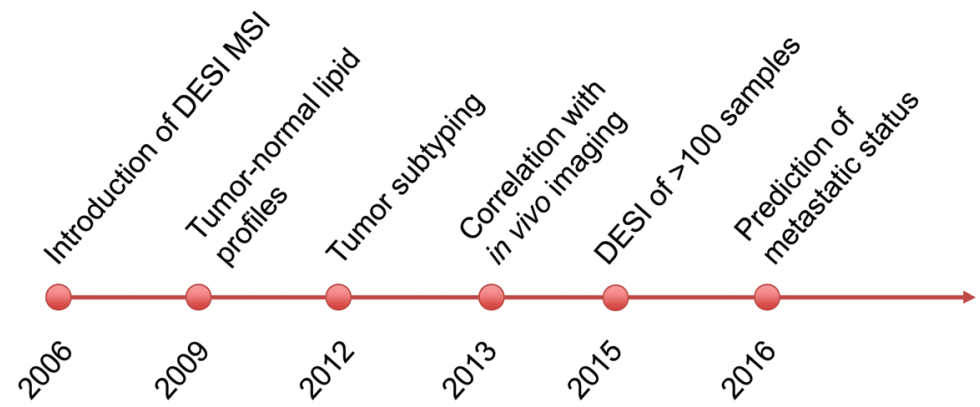

Fig. 4 Highlights and breakthroughs of MALDI- and DESI-MSI in oncology. (a) Highlights in oncology for MALDI-MSI in chronological order and their corresponding references. ${ }^{17,18,52,76,87,118,167,168,170}$ (b) Highlights in oncology for DESI-MSI in chronological order and their corresponding references. ${ }^{173,175,186,253,254}$

to HCC and found increased ubiquitin truncation catalysed by an elevated de novo expression of KLK6 along cancerogenesis. ${ }^{156}$ Similarly, Rebours et al. identified ubiquitin and thymosin-beta 4 as markers of malignant intraductal pancreatic mucinous neoplasms, which are precancerous cystic lesions. ${ }^{157}$ The robustness of the results was further corroborated in larger cohorts using TMAs and endoscopic ultrasound fine-needle aspiration.

Staging. Once the diagnosis of the presence of cancer has been made, the disease stage has to be determined. The first examples of MSI for tumour staging go beyond classical histopathological examination where MALDI-MSI was used for the classification of Her2 receptor status in breast and gastric cancer tissues. ${ }^{117,158}$ Since both routine immunohistochemistry and fluorescence in situ hybridization suffer from subjective interpretation, automated signature-based classification opens new options for an objective Her2 status annotation. The results of Rauser and co-workers also demonstrated that MALDI-MSI can reveal biologically significant molecular details from tissues which are not limited to traditional highabundance proteins. ${ }^{117}$ While the Her2 status is an important determinant for therapy decision-making, the presence of lymph node metastasis is the strongest determinant for patient prognosis. Hence its determination is of utmost importance. In colon cancer tissues, protein expression patterns as detected by MALDI-MSI were able to distinguish between patients with and without metastasis formation. ${ }^{159}$

Prognosis. While patients may share the same diagnosis and tumour stage, they might differ in their prognosis after therapy. MALDI-MSI has been used in many studies to find markers or signatures that can stratify patients according to their survival time after treatment. Several protein signatures were found indicative of unfavourable overall or disease-free survival in intestinal-type gastric cancer, ${ }^{160}$ colon cancer, ${ }^{161}$ sarcomas, ${ }^{162}$ oesophageal cancer, ${ }^{155}$ and lymph node positive breast cancer. ${ }^{163}$ With respect to tumour recurrence, Hardesty et al. were the first to show that protein signatures can be found that can predict relapse in metastatic melanomas. ${ }^{164}$ In another study, modified forms of histone $\mathrm{H} 4$ were found indicative of microvascular invasion in hepatocellular carcinomas (HCC) - a major risk factor in postoperative tumour recurrence and mortality in HCC, usually missed in routine examination from liver biopsy. ${ }^{165}$

Response prediction. Many patients undergo chemotherapeutic treatments, such as neoadjuvant to reduce tumor size before the surgery or adjuvant to reduce cancer recurrence probability after surgery. However, this is a stressful procedure for the patient, which should be avoided for patients who are not responsive to chemotherapeutic treatment. For this reason, there is a strong need for accurate chemotherapy response markers. In breast cancer, MALDI-MS tissue profiling and imaging enabled identification of proteins in pre-treatment biopsies that predict response to neoadjuvant taxanebased therapy. ${ }^{166}$ The knowledge of molecules that are associated with therapy response might also allow insight into the therapy resistance mechanisms of the tumour. This was shown in a study on oesophageal adenocarcinomas where a protein signature was first found to be correlated with the 
chemosensitivity to fluorouracil and cisplatin administration. ${ }^{167}$ This finding initiated subsequent in vitro experiments, which showed that the chemosensitivity to the treatment was correlated to pre-existing defects in mitochondrial respiratory chain complexes of cancer cells, caused by the loss of specific cytochrome $\mathrm{C}$ oxidase subunits.

Molecular histology. Tissue diagnostics can be challenging due to the presence of confounding factors such as inflammation or the lack of a minimum level of differentiation of tumour cells. To illustrate, high-grade sarcomas are diagnostically challenging because of their numerous subtypes that possess overlapping morphology. MALDI-MSI was able to differentiate high-grade osteosarcomas, leiomyosarcomas, and myxofibrosarcomas, and to predict the precursor (and therefore appropriate therapy) of undifferentiated pleomorphic sarcomas. ${ }^{151,162}$ Another pathological challenge is the distinction between atypical Spitzoid neoplasms and melanomas. Based on histology-guided MALDI-MS profiling of the tumour areas, a peptide signature, including signals from actin and vimentin, was able to distinguish Spitz nevi from poor prognosis Spitzoid malignant melanomas with high accuracy. ${ }^{168}$ This study remains unique in MSI clinical applications, since the signature has proved so robust that the study was extended to 11 centres. $^{169}$

Intra-tumour heterogeneity. Tumours are very complex tissue systems and intra-tumour heterogeneity can be perceived as the sum of sub-histological segments. These segments may react differently to therapeutic interventions (e.g. chemo- and radiotherapy) and therefore show characteristic phenotypic behaviour regarding aggressiveness and metastasis formation, thus contributing to the overall clinical disease phenotype. It was demonstrated early on that MSI constitutes a unique tool for the investigation of intra-tumour heterogeneity. ${ }^{170}$ But only recently MALDI-MSI investigations have been extended to the characterization of intra-tumour heterogeneity. ${ }^{171}$ In that study, unsupervised clustering revealed those tumour subpopulations in gastric and breast cancer patients that are associated with different clinical phenotypes such as overall survival or the presence of loco-regional metastases, respectively. This will allow their more in-depth molecular characterization for deriving new tumour subpopulationtailored therapeutic strategies.

Lipid and small metabolite markers. If most of the applications reviewed so far rely on protein signatures (Fig. 4a), it is noteworthy that - especially with the instruction of DESI in 2006 - an increasing number of investigations focus on lipid and metabolic MSI to characterize tumours and surrounding tissues (Fig. 4b). It has become evident already that these signatures can harbour rich information for oncologic research similar to that of proteomics. The prospective collection of samples for metabolic profiling is beneficial as the tissue conservation procedure can strongly influence metabolic activity/ degradation. ${ }^{172}$ In 2015, for instance, Guenther et al. conducted a prospective DESI-MSI study to fingerprint 126 human breast cancer biopsies. ${ }^{173}$ They found substantial differences in fatty acid and phospholipid composition between tumour and healthy glandular tissue and between tumour-associated stroma and normal stromal tissue. Moreover, profiles were correlated with tumour grade and hormone receptor status. The ability of lipid-based DESI-MSI profiles to predict a molecular status of therapeutic relevance was corroborated in a study on colorectal adenocarcinoma, where a multivariate model showed proper separation of the KRAS mutation status in primary tumours and liver metastases. ${ }^{174}$ Eberlin et al. further exploited the ability of DESI-MSI for tumour subtyping in 36 human gliomas. Classifiers based on lipid data showed a high predictive power for subtyping gliomas into oligodendroglioma, astrocytoma or oligoastrocytoma, and assessing the histological grade and tumour cell concentration features. Interestingly, DESI-MSI was also able to distinguish samples characterized by the presence of a specific cell type, namely gemistocytic cells which presented a distinctive lipid profile with abundant fatty acid and fatty acid dimer signals. ${ }^{175}$ In another study, DESI-MSI was used to investigate the lipid composition of human oncocytic, non-oncocytic thyroid tumours, and normal thyroid tissues $(n=45)$. Oncocytic tumours are characterized by an excessive accumulation of mitochondria. The results revealed high abundance of many oxidized cardiolipins in oncocytic tumours. For the first time, an organellespecific biomolecular lipid subclass has been associated with pathological cell subtypes as a cluster for cancer classification on human samples. ${ }^{33}$

MALDI-MSI was also successfully applied for the metabolic profiling of cancer tissues. In a study by Patterson et al., lipid data were obtained from neoadjuvantly-treated colorectal cancer liver metastases. ${ }^{176}$ The signatures were found to accurately compare with histopathologically important features, including different types of necrosis, to assess therapy response objectively. For confirmation, these MSI response scores were also found to correlate with the survival probability of the patients. Shortly afterwards, Lou et al. also ascertained the prognostic value of several small molecules in a cohort of frozen sarcomas. ${ }^{177}$ Buck et al. showed that even in FFPE tissues, clinically relevant information can be conserved in the form of metabolites. They found signatures for the diagnostically challenging separation of oncocytomas from chromophobe renal cell carcinomas, and deoxy sugar acids with sulphate esters for prognostication in patients with oesophageal cancer (Fig. 5b). ${ }^{87}$

Characterization of cancer margins for supporting intraoperative diagnostics. The emergence of ambient ionization techniques and high-speed analyses (Fig. 2f and 3a) has placed MSI in a very competitive position to characterize cancer tissues in a very short time compatible with diagnostic routine. Consequently, MSI has the potential to support decisionmaking based on frozen sections in a perioperative setting. In cancer surgery, the evaluation of resection margins for residual tumour cells is considered to be of utmost importance to avoid a later recurrence or metastasis. ${ }^{35}$ In 2010 and 2014, MALDI-MSI investigations on colorectal and renal tumour margins revealed differences between tumour-adjacent healthy tissue and tumour-remote healthy tissue on both a metabolic 
a)
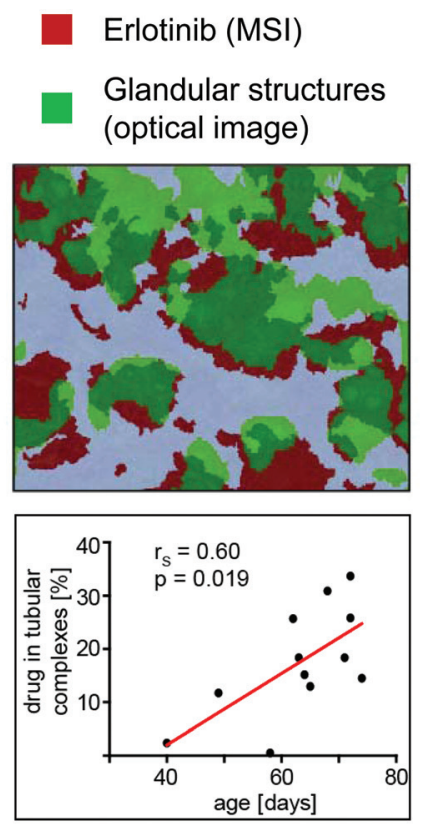

b)

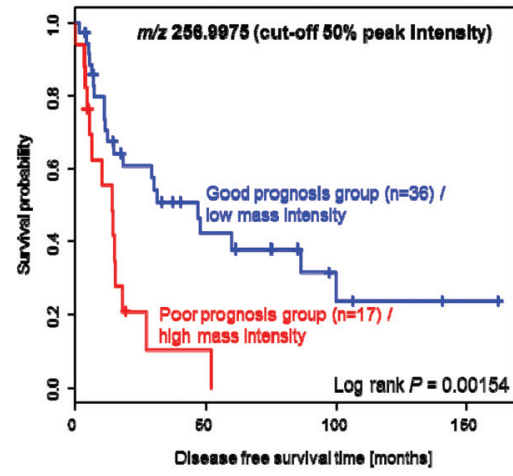

Hlgh mass Intensityl Low mass Intenslty

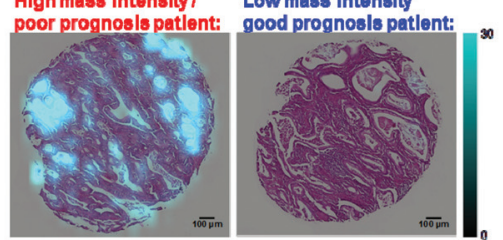

c)
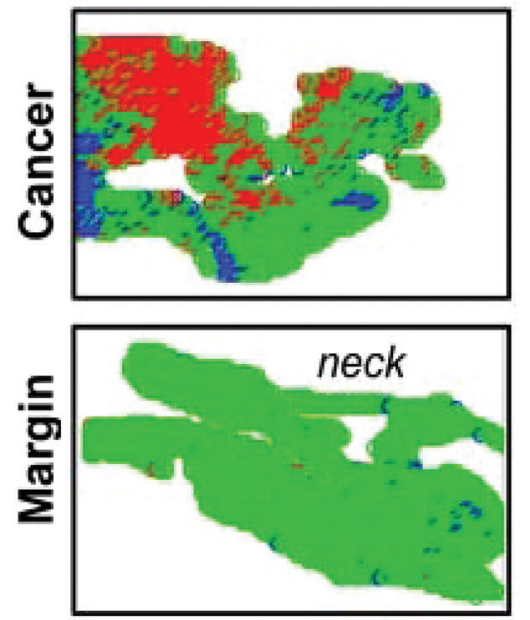

- cancer - normal glands - normal stroma

Clinical research

\section{Pre-clinical research}

\section{Translational research}

Fig. 5 Range of translational research areas covered by MSI studies. We refer to the definition of "translational research" as proposed by Rubio et al. where translational research integrates basic, patient-oriented, and population-based research, with the long-term aim of improving public health. ${ }^{255} \mathrm{MSI}$ can be found across the whole span of translational research. (a) Grüner et al. recently published a pre-clinical study on imaging erlotinib in transgenic mice. This study demonstrated the importance of spatial MS, since the overall survival was only correlated with levels of erlotinib (lower panel) when the drug was localized in the glandular structures of the pancreas (upper panel). Adapted with permission from Grüner et al. ${ }^{198}$ Copyright (2016) American Association for Cancer Research. (b) Buck et al. conducted a biomarker discovery study in formalin-fixed paraffinembedded tissue tissues and found a metabolite (a deoxy sugar acid with sulphate esters), which is located in mucinous areas, with prognostic value for patients with oesophageal cancer. Reprinted with permission from Buck et al. ${ }^{87}$ Copyright (2015) John Wiley and Sons. (c) The type of clinical MSI research with the highest translational character is the perioperative assessment of tumour margins. Eberlin et al. convincingly demonstrated in several studies the accuracy of spatially resolved lipid profiles for detecting tumour residues in surgical specimens, here shown for pancreatic cancer, and its potential superiority, compared to classical histological evaluation, to predict recurrence. ${ }^{183}$

and a proteomic level, ${ }^{178,179}$ showing the necessity to complement classical histopathological inspection of the tumour margins by a molecular technique. Based on these findings, several DESI-MSI studies followed that made use of these tumour-specific profiles to assess tumour margins (Fig. 5c).

The majority of meningiomas are benign tumours, but their resection quality is limited by a proper assessment of the invasion extent of the dura matter by meningioma cells. DESI-MSI could not only distinguish meningioma from dura matter to precisely define the surgical margins, but also determine the meningioma subtype (fibroblastic or meningiothelial) and its NF2 genetic aberration status. ${ }^{180}$ The feasibility of a tumour margin assessment by classifying cancerous and non-cancerous tissues based on molecular signatures in perioperative settings by DESI-MSI was also demonstrated for breast, ${ }^{181}$ gastric, ${ }^{182}$ and pancreatic cancer. ${ }^{183}$

In addition, DESI can also be used to trace known administered or endogenous markers. With respect to the first, Tata et al. used DESI-MSI to detect the contrast agent Gadoteridol in order to image the tumour margins and vasculature in breast cancer xenografts. ${ }^{184}$ An example of the successful visualization of specific endogenous tumour markers by DESI-MSI is 2-hydroxybutyrate, which is generated by isocitrate dehydrogenase 1-mutant gliomas only. ${ }^{184}$ In the same study, the measured data were also fused with an MRI reconstruction of the tumour to improve decision-making. This example shows how ambient MSI techniques can be integrated with other imaging modalities with the ultimate goal of improving intraoperative decisions.

Another important factor for cancer resection is the dispersion of the tumour to the lymphatic system. During surgery the regional cancer dissemination from its primary site can be monitored by a histopathological ex vivo evaluation of sentinel lymph nodes. The presence of metastases in these lymph nodes determines the extent of clearance of the remaining regional lymph nodes. In two DESI-MSI studies on gastric and 
oesophageal cancer, Abbassi-Ghadi et al. found lipid profiles for accurate recognition of affected lymph nodes. ${ }^{185,186}$ While these lipid signatures achieved similar accuracies (100\% and $97.2 \%$ positive and negative predictive values, respectively) as the gold standard immunohistochemistry, ${ }^{186}$ DESI-MSI is much faster and hence could give feedback during the time course of the surgical intervention about the detection of lymph node micrometastases bigger than $200 \mu \mathrm{m}$.

Touch spray and in vivo MS. MSI affiliated techniques are also garnering strong interest for use in surgical diagnostics because they can quickly and accurately classify macroscopic regions on biological samples by exploiting the specificity of local molecular signatures. One of these techniques for the local profiling of tissues is touch spray, where a tiny sample is taken with a needle from tissue and its compounds are exposed to spray ionization in the needle. ${ }^{187}$ Two extensive studies on prostate $(n=170)$ and renal cell cancer $(n=29)$ have investigated the potential of touch spray to distinguish tumour from tumour-free tissues. ${ }^{188,189}$ In both studies touch spray achieved comparable accuracies (>90\%) to DESI-MSI while providing faster analysis times. This calls into question the need to image the tumour margin.

Another interesting technology for surgery is rapid evaporative ionization mass spectrometry (REIMS), which allows near real-time characterization of human tissue in vivo by analysing the smoke released during electrosurgical dissection of the tissue. ${ }^{190}$ Being compatible with current electrosurgical procedures, REIMS has demonstrated great potential for in situ, in vivo and real-time tissue evaluation to improve intraoperative decision-making. Recently, REIMS has been adapted to endoscopic interventions during gastroscopy or colonoscopy, where tissue-specific molecular fingerprints allowed differentiation between healthy mucosa, adenomatous polyps, and cancerous tissue. ${ }^{191,192}$ In colon cancer, REIMS was also able to determine the degree of a tumour's differentiation, lymphovascular invasion, extramural vascular invasion, and lymph node micrometastases. ${ }^{191}$ Based on this first successful evidence, comparable techniques are being developed, such as SpiderMass, which promises equal readout of biomedically relevant information while reducing the invasive condition. ${ }^{193}$

Cross organ studies. Pirro et al. compared DESI-MSI data on both cancerous and corresponding healthy tissues from different human organs including the bladder, kidney (papillary and clear renal cell carcinoma), germ cell, and prostate. This has led to both the identification of cross-tissue cancer markers such as the lipids PI(18:0/20:4) and PS(18:0/18:1) as well as the identification of tissue-specific markers such as cholesterol sulfate for prostate cancer and seminolipid for germ tissue. ${ }^{194}$ Meding et al. have further demonstrated the usefulness of cross-organ molecular profiling in classifying cancers of unknown primary (CUP). ${ }^{195}$ CUP is a clinically challenging diagnosis and a better therapy can be applied if the origin of a metastatic tumour is known. Therefore, proteomic profiles were obtained from six primary cancer types by MALDI-MSI and a classifier was created to distinguish primary tumours. The potential of this classifier for CUP origin deter- mination was successfully demonstrated on colon cancer liver metastasis.

Preclinical models of diseases and drug imaging. While MS molecular profiling of tissues linked with histopathology can be a valuable tool for cancer biomarker discoveries on human samples, MSI is also applied in preclinical research studies where animal models are used in a controlled setting to better understand the mechanisms of pathological disorders.

MYC is one of the most common oncogenes implicated in human cancerogenesis and its relationship to the presence of certain lipids is unknown. Therefore, MYC-induced lymphomas in transgenic mice were investigated by DESI-MSI and a MYC-specific pattern of complex phospholipids was observed. Moreover, this pattern of MYC-induced mouse lymphomas was found to be similar to that of human lymphomas with high MYC expression. ${ }^{196}$ This study shows that in some cases MSI-derived profiles may be translatable from preclinical animal studies to the classification of human tissues. In another study, Grüner et al. used MALDI-MSI to characterize $250 \mu \mathrm{m}$ small precursor lesions of pancreatic ductal adenocarcinoma (PDAC) in genetically engineered mouse models. The analysis of these lesions identified the two proteins ALB1 and TMSB4X as being highly upregulated in the preneoplastic stage compared to a healthy exocrine pancreas. ${ }^{197}$ The validation also showed that TMSB4X was found to be significantly increased in sera of mice with lesions, and that ALB1 upregulation was accompanied by an increased expression of liver-restricted genes. The same researchers also used MALDI-MSI to study the delivery, spatial distribution, and effect of the anti-cancer drug erlotinib on this PDAC mouse model. ${ }^{198}$

For the pharmaceutical industry, compared to autoradiography and LC-ESI-MS/MS on tissue homogenates, MSI represents an unrivalled tool to monitor without labels not only the drug distribution, but also the products of its metabolisation in a tissue or a whole small animal. ${ }^{89,90}$ Even if MSI faces some limitations in the detection and quantification of molecular classes, the endogenous molecular changes linked to the drug and its metabolite distributions may lead toxicological pathology to a new level. For example, a TOF-SIMS study on benzalkonium chloride, a commonly used preservative in eye drops and a reported ocular surface toxin, revealed its penetration deep into ocular structures, with potential deleterious effects. ${ }^{199}$ Likewise a MALDI-MSI nephrotoxicity study on the effects of the anti-cancer drug dabrafenib reported accumulation of the drug's carboxylic acid metabolite in regions of tubular deposits, but not of the drug itself. ${ }^{200}$ This kind of information can be valuable for drug efficiency tests with respect to tissue affinity of the drug and its metabolites. Most of the MSI studies performed so far have been oriented more towards imaging the drug or its metabolite within their histopathological context. As mentioned before, Grüner et al. conducted an MSI study on erlotinib, which was the first drug imaging study to investigate the effect of a drug's distribution on the survival time of mice. ${ }^{198}$ The study also shows the 
importance of the integration of histological information into the analysis, since the overall survival was only found to correlate with the erlotinib levels found in epithelial structures (Fig. 5a). Similarly, AIMS (affinity imaging MS) targets screening of new drug candidates by analysing the specific affinity of compounds to particular tissue regions after in vitro incubation with a mixture of small molecules. ${ }^{201}$

\section{MSI in non-cancer clinical research}

Besides in cancer, MSI has been applied to many other clinical research questions where diseased tissue exhibits a certain spatial complexity.

MSI in neurological diseases. Because of the anatomical and molecular complexity of the central nervous system, MSI has gained wide interest in the investigation of brain-related psychiatric, neurological, and neurodegenerative diseases such as amyotrophic lateral sclerosis, ${ }^{202}$ Alzheimer's disease, ${ }^{203,204}$ migraine $^{205}$ neurotraumas, ${ }^{206}$ Parkinson's disease, ${ }^{207-209}$ schizophrenia, ${ }^{210}$ hunter's disease, ${ }^{211}$ and brain ischemia. ${ }^{212}$ Two reviews have summarized the application of MSI in neurological diseases ${ }^{213,214}$

MSI in cardiovascular diseases. Atherosclerosis is one of the main interests in cardiovascular research, and MSI has given the opportunity to study the molecular content of atherosclerotic plaque and the arterial layers in order to shed light on the molecular processes during plaque formation. It has been shown that high spatial resolution ${ }^{215}$ and 3D imaging ${ }^{137}$ of the plaque is beneficial for the study of the atherosclerotic plaque. Martin-Lorenzo et al. recently reviewed the current status of atherosclerosis investigations by MSI. ${ }^{216}$ Also cardiac tissue has been analysed such as after myocardial infarction ${ }^{217}$ or aortic stenosis, the most common valve disease. ${ }^{218}$ Angel et al. have reviewed MSI of cardiac tissue. ${ }^{219}$

MSI in rheumatology. Investigations into rheumatic disorders by MSI have recently been summarized. ${ }^{220}$ One of the most studied pathologies in rheumatology is osteoarthritis (OA). The pathogenesis involves a progressive degradation of the extracellular matrix of the cartilage, which is formed by chondrocytes, and a remodelling of the synovial membrane and subchondral bone. MSI has been used to study the OA cartilage, synovial membrane, and chondrocytes on metabolic, lipid, protein, and $N$-glycan levels. ${ }^{221}$ In this way, markers have been found that are able to distinguish healthy from OA tissues, ${ }^{222,223}$ as well as markers for chondrogenic differentiation $^{224,225}$ and aging of cartilage. ${ }^{226}$

MSI in nephrology. In nephropathology, MSI has been mainly applied to glomerulonephritis and amyloidosis. The former is a group of kidney diseases which are characterized by the inflammation or scarring of the glomeruli. Magni et al. found in two MALDI-MSI studies several signatures that could distinguish between healthy and diseased glomeruli and between different glomerulonephritis diseases. ${ }^{227,228}$

In contrast, amyloidosis is a disease not exclusively related to the kidney. It is a heterogeneous group of protein misfolding diseases characterized by deposition of amyloid proteins, and diagnosed at the histopathological level with Congo red staining and electron microscopy. Amyloids are fibrillar aggregates of polypeptides in a cross- $\beta$-sheet structure involved in the pathogenesis of amyloidosis. MSI seems promising for subtyping amyloidosis with the aim of revealing amyloidassociated proteins that may provide insights into the pathogenic process of amyloid formation. Casadonte et al. used MALDI-MSI to find peptides in Congo red-positive areas of the kidney. ${ }^{229}$ One of these was identified as vitronectin, which was also found by another MALDI-MSI study and validated using immunohistochemistry across 175 patients with diverse types of amyloidosis and affected tissues. ${ }^{230}$

MSI in ophthalmology. MSI investigations in ophthalmology were recently summarized. ${ }^{231}$ All of the studies show the importance of obtaining spatially defined molecular information from ocular tissues to better characterise several vision-threatening diseases, including age-related macular degeneration, ${ }^{232,233}$ Stargardt's disease, ${ }^{234}$ glaucoma, ${ }^{235}$ and cataracts. $^{236}$ But MSI has also been used to study the biology of the healthy eye, such as the metabolic changes associated with light- and dark-treated retina. ${ }^{237}$

Characterization of the wound healing process. Wound healing appears to be a particularly interesting pathological process to be explored locally by using MSI. Taverna et al. studied cutaneous wound healing in human frozen skin biopsies of decubitus ulcers with different stages and responses of healing. ${ }^{238}$ The spatial character of MALDI-MSI allowed the extraction of proteomic content from the wound bed, adjacent dermis, and hypertrophic epidermis. A signature mainly composed of calcium binding proteins (S-100 molecules) was able to delineate wounds that favourably responded to therapeutic interventions versus those that remain stagnant or intractable in their healing status. ${ }^{238}$ The same authors further investigated the molecular changes during burn wound healing, i.e. from the acute period (days after trauma) to the later hypertrophic scar (months after trauma). ${ }^{239}$ This histology-directed tissue analysis found that the expression of several inflammatory proteins was correlated to the wound healing process, which could be used to predict whether human burn victims are at risk of disfiguring hypertrophic scar formation.

Immunology. Finally, Holzlechner et al. demonstrated that MALDI-MSI can also be used for an in situ molecular characterization of immune cells in human colon tissue, which is by nature strongly infiltrated with immune cells. ${ }^{53}$ In this example, several proteinaceous markers were identified that co-localized with CD3+ T-lymphocytes and CD206+ macrophages. Because different types of immune cells can be visualized and molecularly assessed in their natural environment, further studies of the cross talk between lymphocytes and their tissue microenvironment will be enabled by this method. In a previous study of autoimmune liver diseases, it was already shown that protein profiles of inflammatory infiltrates were different from bile ducts and hepatocytes. ${ }^{240}$ Interestingly, the authors could not find any proteins that could distinguish, with certainty, between the three major forms of autoimmune liver. 


\section{The present challenges in translational research performed with MSI}

As shown in the previous section, MSI contributes novel and valuable information on many biomedical research questions. But all of these applications of MSI have also revealed specific limitations with respect to the requirements of clinical research which has two main interests: first, improving the diagnostic certainty through biomarker discovery, and second, improving the understanding of the biological mechanisms of the studied pathology with the final aim of being able to develop novel therapies.

Biomarker discovery is all about reproducibility and accuracy, i.e. to find hidden markers that most exactly stratify patients according to a certain clinical feature in different labs with the same precision. Similar to other omics techniques, MSI produces high-dimensional data sets on a sample number, which is usually orders of magnitude lower than the number of detected features. In this scenario, the resulting data will suffer from the so-called "curse of dimensionality," which can lead to potentially false-positive discoveries and to overfitting of multivariate classifiers. The final consequence of both is non-reproducibility. ${ }^{241}$ A suitable validation of the results can overcome this problem. ${ }^{242}$ There are different levels of validation, each providing a different level of evidence for the original finding. Validation approaches range from technical replicates, the use of independent methods or sample cohorts to multicentre studies, which provide the highest level of evidence as it removes biases based on laboratory conditions (Fig. 6). ${ }^{243}$

Many MSI studies have validated their results in different ways. If protocols and antibodies are available, protein biomarker findings have been mostly validated using immunohistochemistry as an independent technique. ${ }^{244}$ However, when it comes to multivariate patterns, the classificatory combination

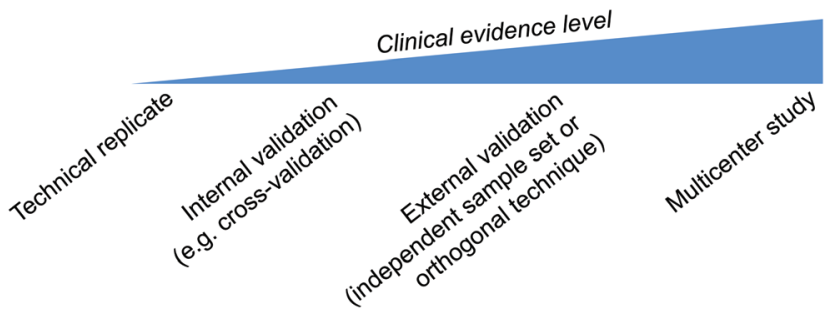

Fig. 6 Measures to assess the clinical evidence levels of potential biomarkers. For a successful translation, results from clinical research have to prove reproducible by a proper validation. There are different strategies, which provide different levels of evidence for the correctness of the original finding. The lowest level of evidence is provided by technical replicates. But most of the validations performed in biomarker discovery studies make use of either an internal validation or external validation step. The internal validation can involve the testing of the accuracy of a uni- or multivariate marker using cross-validation techniques, or the use of another assay for trying to read out the same information from the same samples. An external validation includes an independent sample set and may be performed by another assay. But the highest level of evidence is provided by multi-centre studies on several independent sample cohorts. of single signals is only replicable by the same methodology. In this case, either a computational solution can be employed (e.g. by using cross-validation), ${ }^{244}$ or the classifier must be tested on a second independent sample cohort. ${ }^{117}$ But the ultimate step from the clinical exploratory phase to the phase of clinical assay validation is a multicentre study.

So far only one MSI biomarker publication has been based on a multicentre study with the aim of identifying markers for the activation of tumour stroma in breast cancer. ${ }^{52}$ There are some conclusions that can be drawn from this study. First, three out of four univariate protein signals were found reproducible between the two centres. This indicates high specificity in the MSI results, which might be attributed to the histological specificity of the MSI approach. Second, the multivariate classifier's accuracy (a non-significant drop from 100\% in the first to $81 \%$ in the second centre) exhibited the highest difference between centres, which is in line with the experience from gene-expression studies and hence suggests a more rigorous validation over more centres or the involvement of more samples. ${ }^{245}$ Lastly, the biological effect was robust enough despite minor differences in the experimental protocols between the centres and composition of the patient cohorts. However, future multi-centre studies should standardize their protocols in order to become more reproducible for clinically relevant questions based on smaller biochemical changes at danger to be masked by inter-centre variance.

To overcome inter-centre variance MSI experiments can also be centralized for the analysis of samples from difference centres. This has been done for a study on over 250 atypical Spitzoid neoplasms, which was able to find clinical associations of MSI data across centres from 11 countries and 11 US institutions. ${ }^{169}$ This is remarkable as the study was performed not only on FFPE specimens but also on full sections of those samples. To put this into context, most MSI biomarker studies reporting results that involve FFPE samples in this magnitude have been performed on tissue microarrays to reduce the intersample technical variance caused by FFPE sample preparation, which is chemically intense due to antigen retrieval and in situ enzymatic digestion. Measures of reproducibility have therefore been proposed with the aim of assessing the level of reproducibility of FFPE sample preparation. ${ }^{79,82}$

Another important factor in on-tissue digestion is the chemical microenvironment of different regions within a tissue, which has been shown to cause differences in digestion dynamics. ${ }^{80}$ Furthermore, these differences in the chemical nature of the tissue extend to all chemical surface reactions, even beyond digestion. It has been demonstrated that regional differences in molecular compositions can also affect ionization efficiency due to ion suppression effects. ${ }^{26}$ Although all of these effects must be better characterized to draw better quantitative conclusions, ion suppression effects are not necessarily negative as they are specific to each tissue and therefore help to differentiate tissue types and enable tissue classification. However, these effects might become a problem for validation by other analytical platforms that try to reproduce the same results but are not "positively" affected by the on-tissue ion suppression (e.g. LC-MS). 
All the factors mentioned above influence reproducibility and hence measures or quality controls are desirable that could correct for these effects, or at least indicate the quality of the tissue. The description of a sample's properties can also be extended to its quality in terms of conservation of the molecular state of the tissue at the time of sampling. A few laboratories have investigated the effects of degradation and aging on MSI data on the molecular content of the samples. ${ }^{24,247}$ Significant changes have been found to occur in tissues within $30 \mathrm{~s}$ at the protein level when exposed to room temperature, ${ }^{248}$ and even in lipids after 7 months of storage at $-80^{\circ} \mathrm{C} .{ }^{249}$

The second goal of clinical research, namely the understanding of biological and pathological mechanisms, depends on the coverage of the studied molecular class, e.g. the number of detected proteins from the whole proteome. This is currently hampered by the limited analytical depth of MSI in terms of coverage and identification capabilities. The lack of analytical purification and separation steps makes direct ontissue identification through parent ion isolation and fragmentation challenging.

In consequence, small molecules and peptides are now mainly identified by mass matching of the observed $\mathrm{m} / \mathrm{z}$ value, usually determined with high-mass resolution and accuracy mass spectrometers such as FT-ICR, with public or samplespecific databases created from parallel extract-based LC-MS/ MS experiments. ${ }^{78,87}$ However, the number of identified molecules is still one or two magnitudes lower than that from the state-of-the-art bottom-up proteomics and metabolomics experiments. A promising way of combining the analytical depth of liquid extraction techniques and MSI is local extraction such as LESA. It has already been successfully applied in the spatial profiling of proteins and metabolites on tissue surfaces. ${ }^{38,250}$ However, there is still a trade-off between spatial resolution and analytical depth.

Another issue in MSI is data analysis and management. With the availability of high-throughput MSI systems, high spatially resolved 2D or 3D data sets will become standard, including in clinical research. As the data gain in quantity, the full exploitation of these data sets will require many innovations in processing software. For instance, single-cell MSI must be matched by single-cell virtual micro-dissection. The latter can only be enabled by new, accurate routines for the coregistration of the histological image in order to lower recent coregistration error, ${ }^{251}$ and by the automated annotation of the histological images by algorithms, as manual annotation will become unfeasible on a single-cell level. This is especially true for 3D-MSI data sets, which face an additional challenge at the single-cell level: improving the alignment between the different consecutive slides in order to make the alignment error smaller than the MSI pixel size.

\section{Conclusions}

The cytological and histological specificity offered by MSI (Fig. 1), while leaving tissue intact, has made it a unique tool in biomedical research. As shown in this review, many studies have made use of this property to address research questions which deal with complex structures in tissues such as brains, eyes, joints, wounds, atherosclerotic plaques, etc. But the driving field of activity in MSI is and has been oncology, where MSI has allowed the extraction of tumour-specific molecular information for various purposes, such as biomarker discovery for diagnosis and prognosis, investigation of intratumor heterogeneity, classification of tumour margins, and the imaging of anticancer drugs in animal models (Fig. 4), thereby covering all stages of translational research from pre-clinical to clinical research (Fig. 5). Particularly because of its capability to visualize exogenous compounds and their metabolites in tissues, MSI has become extremely valuable for pharmaceutical and biotechnology companies. Therefore, the interest in the technology is growing, which also drives technical developments in the field.

MSI has undergone many technical improvements in the last few years. New atmospheric pressure ion sources have gathered interest in MSI, especially with the introduction of DESI (Fig. 2). Sample preparation-free measurements make it possible now to obtain MSI data minutes after sectioning. But MALDI-MSI has also caught up. MALDI-TOF systems are now able to deliver in the same timeframe even higher spatially resolved molecular images, though at the expense of sample preparation. Both developments now allow clinical research involving large sample cohorts in a high-throughput manner (Fig. 3). If MSI can overcome its final limitations, by proving sufficient reproducibility in between-centre studies (Fig. 6) and improving its molecular coverage - especially the proteome and identification, then it will not only continue to have a large impact on clinical and pre-clinical research, but will also make the final step from research to clinical application.

\section{Acknowledgements}

This work has been made possible with support from the Dutch Province of Limburg. BB acknowledges the European Union (ERA-NET: TRANSCAN 2), ITEA and RVO (ITEA 151003/ ITEA 14001) for their financial support. The authors thank Stacey Meulenberg for her excellent technical assistance. We are thankful to Marc Bemelmans (Surgery Department), Mari van den Hout and Lindsay Hewitt (both Pathology Department) from the Maastricht University Medical Centre (MUMC+) for providing the tissues and pathological annotations for Fig. 1 and 3. We are very grateful to Justin Baker for editing the manuscript.

\section{References}

1 J. Y. Cho and H. J. Sung, Expert Rev. Proteomics, 2009, 6, 27-42.

2 P. Mallick and B. Kuster, Nat. Biotechnol., 2010, 28, 695709. 
3 Y. J. Xue, H. Gao, Q. C. Ji, Z. Lam, X. Fang, Z. J. Lin, M. Hoffman, D. Schulz-Jander and N. Weng, Bioanalysis, 2012, 4, 2637-2653.

4 K. Suhre, J. Endocrinol., 2014, 221, R75-R85.

5 V. Espina, J. D. Wulfkuhle, V. S. Calvert, A. VanMeter, W. Zhou, G. Coukos, D. H. Geho, E. F. Petricoin 3rd and L. A. Liotta, Nat. Protoc., 2006, 1, 586-603.

6 D. J. Gauthier, J. A. Sobota, F. Ferraro, R. E. Mains and C. Lazure, Proteomics, 2008, 8, 3848-3861.

7 A. Walch, S. Rauser, S. O. Deininger and H. Hofler, Histochem. Cell Biol., 2008, 130, 421-434.

8 S. S. Rubakhin, J. C. Jurchen, E. B. Monroe and J. V. Sweedler, Drug Discovery Today, 2005, 10, 823-837.

9 K. Schwamborn, Adv. Cancer Res., 2017, 134, 1-26.

10 S. Rauser, S. O. Deininger, D. Suckau, H. Hofler and A. Walch, Expert Rev. Proteomics, 2010, 7, 927-941.

11 K. Schwamborn, M. Kriegsmann and W. Weichert, Biochim. Biophys. Acta, 2017, 1865, 776-783.

12 C. Wu, A. L. Dill, L. S. Eberlin, R. G. Cooks and D. R. Ifa, Mass Spectrom. Rev., 2013, 32, 218-243.

13 R. Casadonte and R. M. Caprioli, Nat. Protoc., 2011, 6, 1695-1709.

14 A. Ly, A. Buck, B. Balluff, N. Sun, K. Gorzolka, A. Feuchtinger, K. P. Janssen, P. J. Kuppen, C. J. van de Velde, G. Weirich, F. Erlmeier, R. Langer, M. Aubele, H. Zitzelsberger, L. McDonnell, M. Aichler and A. Walch, Nat. Protoc., 2016, 11, 1428-1443.

15 R. M. A. Heeren, Int. J. Mass Spectrom., 2015, 377, 672680.

16 R. N. Sodhi, Analyst, 2004, 129, 483-487.

17 R. M. Caprioli, T. B. Farmer and J. Gile, Anal. Chem., 1997, 69, 4751-4760.

18 P. Chaurand, S. A. Schwartz, D. Billheimer, B. J. Xu, A. Crecelius and R. M. Caprioli, Anal. Chem., 2004, 76, 1145-1155.

19 P. J. Todd, T. G. Schaaff, P. Chaurand and R. M. Caprioli, J. Mass Spectrom., 2001, 36, 355-369.

20 J. O. Gustafsson, M. K. Oehler, A. Ruszkiewicz, S. R. McColl and P. Hoffmann, Int. J. Mol. Sci., 2011, 12, 773-794.

21 J. A. Hankin, R. M. Barkley and R. C. Murphy, J. Am. Soc. Mass Spectrom., 2007, 18, 1646-1652.

22 T. C. Baker, J. Han and C. H. Borchers, Curr. Opin. Biotechnol, 2016, 43, 62-69.

23 J. Yang and R. M. Caprioli, Anal. Chem., 2011, 83, 57285734.

24 B. Cillero-Pastor and R. M. Heeren, J. Proteome Res., 2014, 13, 325-335.

25 C. Esteve, E. A. Tolner, R. Shyti, A. M. van den Maagdenberg and L. A. McDonnell, Metabolomics, 2016, $12,30$.

26 I. Lanekoff, S. L. Stevens, M. P. Stenzel-Poore and J. Laskin, Analyst, 2014, 139, 3528-3532.

27 S. O. Deininger, D. S. Cornett, R. Paape, M. Becker, C. Pineau, S. Rauser, A. Walch and E. Wolski, Anal. Bioanal. Chem., 2011, 401, 167-181.
28 Z. Takats, J. M. Wiseman, B. Gologan and R. G. Cooks, Anal. Chem., 2004, 76, 4050-4058.

29 T. Porta, A. Lesur, E. Varesio and G. Hopfgartner, Anal. Bioanal. Chem., 2015, 407, 2177-2187.

30 J. M. Spraggins and R. M. Caprioli, J. Am. Soc. Mass Spectrom., 2011, 22, 1022-1031.

31 J. M. Wiseman, D. R. Ifa, Y. Zhu, C. B. Kissinger, N. E. Manicke, P. T. Kissinger and R. G. Cooks, Proc. Natl. Acad. Sci. U. S. A., 2008, 105, 18120-18125.

32 A. M. Fernandes, P. H. Vendramini, R. Galaverna, N. V. Schwab, L. C. Alberici, R. Augusti, R. F. Castilho and M. N. Eberlin, J. Am. Soc. Mass Spectrom., 2016, 27, 19441951.

33 J. Zhang, W. Yu, S. W. Ryu, J. Lin, G. Buentello, R. Tibshirani, J. Suliburk and L. S. Eberlin, Cancer Res., 2016, 76, 6588-6597.

34 D. Lostun, C. J. Perez, P. Licence, D. A. Barrett and D. R. Ifa, Anal. Chem., 2015, 87, 3286-3293.

35 D. R. Ifa and L. S. Eberlin, Clin. Chem., 2016, 62, 111-123.

36 J. Laskin, B. S. Heath, P. J. Roach, L. Cazares and O. J. Semmes, Anal. Chem., 2012, 84, 141-148.

37 C. C. Hsu, P. T. Chou and R. N. Zare, Anal. Chem., 2015, 87, 11171-11175.

38 J. Sarsby, N. J. Martin, P. F. Lalor, J. Bunch and H. J. Cooper, J. Am. Soc. Mass Spectrom., 2014, 25, 19531961.

39 M. Wisztorski, A. Desmons, J. Quanico, B. Fatou, J. P. Gimeno, J. Franck, M. Salzet and I. Fournier, Proteomics, 2016, 16, 1622-1632.

40 P. Nemes and A. Vertes, Anal. Chem., 2007, 79, 8098-8106.

41 A. Sussulini, J. S. Becker and J. S. Becker, Mass Spectrom. Rev., 2017, 36, 47-57.

42 O. Yanes, H. K. Woo, T. R. Northen, S. R. Oppenheimer, L. Shriver, J. Apon, M. N. Estrada, M. J. Potchoiba, R. Steenwyk, M. Manchester and G. Siuzdak, Anal. Chem., 2009, 81, 2969-2975.

43 B. M. Prentice and R. M. Caprioli, Postdoc. J., 2016, 4, 3-13.

44 N. Ogrinc Potocnik, T. Porta, M. Becker, R. M. Heeren and S. R. Ellis, Rapid Commun. Mass Spectrom., 2015, 29, 21952203.

45 J. M. Spraggins, D. G. Rizzo, J. L. Moore, M. J. Noto, E. P. Skaar and R. M. Caprioli, Proteomics, 2016, 16, 16781689.

46 R. T. Steven, A. Dexter and J. Bunch, Methods, 2016, 104, 101-110.

47 B. M. Prentice, C. W. Chumbley and R. M. Caprioli, J. Mass Spectrom., 2015, 50, 703-710.

48 S. Steurer, C. Borkowski, S. Odinga, M. Buchholz, C. Koop, H. Huland, M. Becker, M. Witt, D. Trede, M. Omidi, O. Kraus, A. S. Bahar, A. S. Seddiqi, J. M. Singer, M. Kwiatkowski, M. Trusch, R. Simon, M. Wurlitzer, S. Minner, T. Schlomm, G. Sauter and H. Schluter, Int. J. Cancer, 2013, 133, 920-928.

49 E. A. Jones, M. Towers, B. Shrestha, P. Hart, R. Chapman and E. Claude, DESI Imaging at varying acquisition rates 
with real time imaging display for optimized tissue imaging, 65th American Society for Mass Spectrometry (ASMS) Conference, San Antonio, 2016.

50 M. R. Junttila and F. J. de Sauvage, Nature, 2013, 501, 346354.

51 E. J. Lanni, S. S. Rubakhin and J. V. Sweedler, J. Proteomics, 2012, 75, 5036-5051.

52 T. J. Dekker, B. D. Balluff, E. A. Jones, C. D. Schone, M. Schmitt, M. Aubele, J. R. Kroep, V. T. Smit, R. A. Tollenaar, W. E. Mesker, A. Walch and L. A. McDonnell, J. Proteome Res., 2014, 13, 4730-4738.

53 M. Holzlechner, K. Strasser, E. Zareva, L. Steinhauser, H. Birnleitner, A. Beer, M. Bergmann, R. Oehler and M. Marchetti-Deschmann, J. Proteome Res., 2017, 16, 6576.

54 L. Carlred, V. Vukojevic, B. Johansson, M. Schalling, F. Hook and P. Sjovall, Biointerphases, 2016, 11, $02 \mathrm{~A} 312$.

55 A. F. Altelaar, S. L. Luxembourg, L. A. McDonnell, S. R. Piersma and R. M. Heeren, Nat. Protoc., 2007, 2, 1185-1196.

56 E. M. Weaver and A. B. Hummon, Adv. Drug Delivery Rev., 2013, 65, 1039-1055.

57 J. Brison, D. S. Benoit, S. Muramoto, M. Robinson, P. S. Stayton and D. G. Castner, Surf. Interface Anal., 2011, 43, 354-357.

58 A. D. Feenstra, M. E. Duenas and Y. J. Lee, J. Am. Soc. Mass Spectrom., 2017, 28, 434-442.

59 B. Spengler and M. Hubert, J. Am. Soc. Mass Spectrom., 2002, 13, 735-748.

60 M. Kompauer, S. Heiles and B. Spengler, Nat. Methods, 2017, 14, 90-96.

61 L. A. McDonnell and R. M. Heeren, Mass Spectrom. Rev., 2007, 26, 606-643.

62 G. Thiery-Lavenant, A. I. Zavalin and R. M. Caprioli, J. Am. Soc. Mass Spectrom., 2013, 24, 609-614.

63 B. Bodenmiller, Cell Syst., 2016, 2, 225-238.

64 C. Giesen, H. A. Wang, D. Schapiro, N. Zivanovic, A. Jacobs, B. Hattendorf, P. J. Schuffler, D. Grolimund, J. M. Buhmann, S. Brandt, Z. Varga, P. J. Wild, D. Gunther and B. Bodenmiller, Nat. Methods, 2014, 11, 417-422.

65 B. Enthaler, T. Bussmann, J. K. Pruns, C. Rapp, M. Fischer and J. P. Vietzke, Rapid Commun. Mass Spectrom., 2013, 27, 878-884.

66 R. Lemaire, M. Wisztorski, A. Desmons, J. C. Tabet, R. Day, M. Salzet and I. Fournier, Anal. Chem., 2006, 78, 7145-7153.

67 M. Martin-Lorenzo, B. Balluff, A. Sanz-Maroto, R. J. van Zeijl, F. Vivanco, G. Alvarez-Llamas and L. A. McDonnell, J. Proteomics, 2014, 108, 465-468.

68 E. H. Seeley, S. R. Oppenheimer, D. Mi, P. Chaurand and R. M. Caprioli, J. Am. Soc. Mass Spectrom., 2008, 19, 10691077.

69 A. Thomas, N. H. Patterson, J. Laveaux Charbonneau and P. Chaurand, J. Mass Spectrom., 2013, 48, 42-48.

70 E. Gemperline, S. Rawson and L. Li, Anal. Chem., 2014, 86, 10030-10035.
71 J. Yang and R. M. Caprioli, Anal. Chem., 2013, 85, 29072912.

72 F. P. Barre, B. Flinders, J. P. Garcia, I. Jansen, L. R. Huizing, T. Porta, L. B. Creemers, R. M. Heeren and B. Cillero-Pastor, Anal. Chem., 2016, 88, 12051-12059.

73 X. Liu and A. B. Hummon, Sci. Rep., 2016, 6, 38507.

74 J. Franck, M. E. Ayed, M. Wisztorski, M. Salzet and I. Fournier, Methods Mol. Biol., 2010, 656, 323-338.

75 C. Wu, D. R. Ifa, N. E. Manicke and R. G. Cooks, Anal. Chem., 2009, 81, 7618-7624.

76 R. Lemaire, A. Desmons, J. C. Tabet, R. Day, M. Salzet and I. Fournier, J. Proteome Res., 2007, 6, 1295-1305.

77 J. O. Gustafsson, M. K. Oehler, S. R. McColl and P. Hoffmann, J. Proteome Res., 2010, 9, 4315-4328.

78 B. Heijs, R. J. Carreira, E. A. Tolner, A. H. de Ru, A. M. van den Maagdenberg, P. A. van Veelen and L. A. McDonnell, Anal. Chem., 2015, 87, 1867-1875.

79 H. C. Diehl, B. Beine, J. Elm, D. Trede, M. Ahrens, M. Eisenacher, K. Marcus, H. E. Meyer and C. Henkel, Anal. Bioanal. Chem., 2015, 407, 2223-2243.

80 B. Heijs, E. A. Tolner, J. V. Bovee, A. M. van den Maagdenberg and L. A. McDonnell, J. Proteome Res., 2015, 14, 5348-5354.

81 J. Oetjen, D. Lachmund, A. Palmer, T. Alexandrov, M. Becker, T. Boskamp and P. Maass, Anal. Bioanal. Chem., 2016, 408, 6729-6740.

82 K. Erich, D. A. Sammour, A. Marx and C. Hopf, Biochim. Biophys. Acta, 2017, 1865, 907-915.

83 T. W. Powers, B. A. Neely, Y. Shao, H. Tang, D. A. Troyer, A. S. Mehta, B. B. Haab and R. R. Drake, PLoS One, 2014, 9, e106255.

84 T. W. Powers, E. E. Jones, L. R. Betesh, P. R. Romano, P. Gao, J. A. Copland, A. S. Mehta and R. R. Drake, Anal. Chem., 2013, 85, 9799-9806.

85 S. Holst, B. Heijs, N. de Haan, R. J. van Zeijl, I. H. Briairede Bruijn, G. W. van Pelt, A. S. Mehta, P. M. Angel, W. E. Mesker, R. A. Tollenaar, R. R. Drake, J. V. Bovee, L. A. McDonnell and M. Wuhrer, Anal. Chem., 2016, 88, 5904-5913.

86 B. Heijs, S. Holst, I. H. Briaire-de Bruijn, G. W. van Pelt, A. H. de Ru, P. A. van Veelen, R. R. Drake, A. S. Mehta, W. E. Mesker, R. A. Tollenaar, J. V. Bovee, M. Wuhrer and L. A. McDonnell, Anal. Chem., 2016, 88, 7745-7753.

87 A. Buck, A. Ly, B. Balluff, N. Sun, K. Gorzolka, A. Feuchtinger, K. P. Janssen, P. J. Kuppen, C. J. van de Velde, G. Weirich, F. Erlmeier, R. Langer, M. Aubele, H. Zitzelsberger, M. Aichler and A. Walch, J. Pathol., 2015, 237, 123-132.

88 P. Hatsis, S. Brombacher, J. Corr, P. Kovarik and D. A. Volmer, Rapid Commun. Mass Spectrom., 2003, 17, 2303-2309.

89 A. Nilsson, R. J. Goodwin, M. Shariatgorji, T. Vallianatou, P. J. Webborn and P. E. Andren, Anal. Chem., 2015, 87, 1437-1455.

90 B. Prideaux and M. Stoeckli, J. Proteomics, 2012, 75, 49995013. 
91 B. M. Prentice, C. W. Chumbley and R. M. Caprioli, J. Am. Soc. Mass Spectrom., 2017, 28, 136-144.

92 I. M. Taban, A. F. Altelaar, Y. E. van der Burgt, L. A. McDonnell, R. M. Heeren, J. Fuchser and G. Baykut, J. Am. Soc. Mass Spectrom., 2007, 18, 145-151.

93 A. Rompp, S. Guenther, Z. Takats and B. Spengler, Anal. Bioanal. Chem., 2011, 401, 65-73.

94 A. Rompp and B. Spengler, Histochem. Cell Biol., 2013, 139, 759-783.

95 G. Robichaud, J. A. Barry, K. P. Garrard and D. C. Muddiman, J. Am. Soc. Mass Spectrom., 2013, 24, 92100.

96 M. C. Djidja, E. Claude, M. F. Snel, S. Francese, P. Scriven, V. Carolan and M. R. Clench, Anal. Bioanal. Chem., 2010, 397, 587-601.

97 M. R. Groseclose, P. P. Massion, P. Chaurand and R. M. Caprioli, Proteomics, 2008, 8, 3715-3724.

98 D. A. Pirman and R. A. Yost, Anal. Chem., 2011, 83, 85758581.

99 G. Hopfgartner, E. Varesio and M. Stoeckli, Rapid Commun. Mass Spectrom., 2009, 23, 733-736.

100 T. Porta, C. Grivet, T. Kraemer, E. Varesio and G. Hopfgartner, Anal. Chem., 2011, 83, 4266-4272.

101 B. Prideaux, V. Dartois, D. Staab, D. M. Weiner, A. Goh, L. E. Via, C. E. Barry 3rd and M. Stoeckli, Anal. Chem., 2011, 83, 2112-2118.

102 G. L. Fisher, A. L. Bruinen, N. Ogrinc Potocnik, J. S. Hammond, S. R. Bryan, P. E. Larson and R. M. Heeren, Anal. Chem., 2016, 88, 6433-6440.

103 S. N. Jackson, M. Ugarov, J. D. Post, T. Egan, D. Langlais, J. A. Schultz and A. S. Woods, J. Am. Soc. Mass Spectrom., 2008, 19, 1655-1662.

104 C. D. Chouinard, M. S. Wei, C. R. Beekman, R. H. Kemperman and R. A. Yost, Clin. Chem., 2016, 62, 124-133.

105 T. Porta, E. Varesio and G. Hopfgartner, Anal. Chem., 2013, 85, 11771-11779.

106 K. Chughtai, L. Jiang, T. R. Greenwood, K. Glunde and R. M. Heeren, J. Lipid Res., 2013, 54, 333-344.

107 K. Skraskova, E. Claude, E. A. Jones, M. Towers, S. R. Ellis and R. M. Heeren, Methods, 2016, 104, 69-78.

108 A. Roux, L. Muller, S. N. Jackson, J. Post, K. Baldwin, B. Hoffer, C. D. Balaban, D. Barbacci, J. A. Schultz, S. Gouty, B. M. Cox and A. S. Woods, J. Neurosci. Methods, 2016, 272, 19-32.

109 L. M. Cole, K. Mahmoud, S. Haywood-Small, G. M. Tozer, D. P. Smith and M. R. Clench, Rapid Commun. Mass Spectrom., 2013, 27, 2355-2362.

110 M. C. Djidja, S. Francese, P. M. Loadman, C. W. Sutton, P. Scriven, E. Claude, M. F. Snel, J. Franck, M. Salzet and M. R. Clench, Proteomics, 2009, 9, 2750-2763.

111 R. L. Griffiths, A. J. Creese, A. M. Race, J. Bunch and H. J. Cooper, Anal. Chem., 2016, 88, 6758-6766.

112 J. Sarsby, R. L. Griffiths, A. M. Race, J. Bunch, E. C. Randall, A. J. Creese and H. J. Cooper, Anal. Chem., 2015, 87, 6794-6800.
113 G. Terral, A. Beck and S. Cianferani, J. Chromatogr. B: Anal. Technol. Biomed. Life Sci., 2016, 1032, 79-90.

114 C. L. Feider, N. Elizondo and L. S. Eberlin, Anal. Chem., 2016, 88, 11533-11541.

115 J. Soltwisch, H. Kettling, S. Vens-Cappell, M. Wiegelmann, J. Muthing and K. Dreisewerd, Science, 2015, 348, 211215.

116 S. K. Maier, H. Hahne, A. M. Gholami, B. Balluff, S. Meding, C. Schoene, A. K. Walch and B. Kuster, Mol. Cell. Proteomics, 2013, 12, 2901-2910.

117 S. Rauser, C. Marquardt, B. Balluff, S. O. Deininger, C. Albers, E. Belau, R. Hartmer, D. Suckau, K. Specht, M. P. Ebert, M. Schmitt, M. Aubele, H. Hofler and A. Walch, J. Proteome Res., 2010, 9, 1854-1863.

118 K. Yanagisawa, Y. Shyr, B. J. Xu, P. P. Massion, P. H. Larsen, B. C. White, J. R. Roberts, M. Edgerton, A. Gonzalez, S. Nadaf, J. H. Moore, R. M. Caprioli and D. P. Carbone, Lancet, 2003, 362, 433-439.

119 J. M. Spraggins, D. G. Rizzo, J. L. Moore, K. L. Rose, N. D. Hammer, E. P. Skaar and R. M. Caprioli, J. Am. Soc. Mass Spectrom., 2015, 26, 974-985.

120 L. A. McDonnell, A. Walch, M. Stoeckli and G. L. Corthals, J. Proteome Res., 2014, 13, 1138-1142.

121 Y. Schober, T. Schramm, B. Spengler and A. Rompp, Rapid Commun. Mass Spectrom., 2011, 25, 2475-2483.

122 M. R. Groseclose, M. Andersson, W. M. Hardesty and R. M. Caprioli, J. Mass Spectrom., 2007, 42, 254-262.

123 H. Ye, L. Hui, K. Kellersberger and L. Li, J. Am. Soc. Mass Spectrom., 2013, 24, 134-147.

124 O. J. Gustafsson, J. S. Eddes, S. Meding, S. R. McColl, M. K. Oehler and P. Hoffmann, Rapid Commun. Mass Spectrom., 2013, 27, 655-670.

125 E. E. Jones, T. W. Powers, B. A. Neely, L. H. Cazares, D. A. Troyer, A. S. Parker and R. R. Drake, Proteomics, 2014, 14, 924-935.

126 S. Giordano, L. Morosi, P. Veglianese, S. A. Licandro, R. Frapolli, M. Zucchetti, G. Cappelletti, L. Falciola, V. Pifferi, S. Visentin, M. D'Incalci and E. Davoli, Sci. Rep., 2016, 6, 37027.

127 J. D. Watrous, V. V. Phelan, C. C. Hsu, W. J. Moree, B. M. Duggan, T. Alexandrov and P. C. Dorrestein, ISME J, 2013, 7, 770-780.

128 J. M. Lotz, F. Hoffmann, J. Lotz, S. Heldmann, D. Trede, J. Oetjen, M. Becker, G. Ernst, P. Maas, T. Alexandrov, O. Guntinas-Lichius, H. Thiele and F. von Eggeling, Biochim. Biophys. Acta, 2017, 1865, 946-956.

129 X. Xiong, W. Xu, L. S. Eberlin, J. M. Wiseman, X. Fang, Y. Jiang, Z. Huang, Y. Zhang, R. G. Cooks and Z. Ouyang, J. Am. Soc. Mass Spectrom., 2012, 23, 1147-1156.

130 Q. P. Vanbellingen, A. Castellanos, M. Rodriguez-Silva, I. Paudel, J. W. Chambers and F. A. Fernandez-Lima, J. Am. Soc. Mass Spectrom., 2016, 27, 2033-2040.

131 J. S. Fletcher, N. P. Lockyer and J. C. Vickerman, Mass Spectrom. Rev., 2011, 30, 142-174.

132 G. L. Fisher, A. M. Belu, C. M. Mahoney, K. Wormuth and N. Sanada, Anal. Chem., 2009, 81, 9930-9940. 
133 J. S. Fletcher and J. C. Vickerman, Anal. Bioanal. Chem., 2010, 396, 85-104.

134 S. Van Nuffel, C. Parmenter, D. J. Scurr, N. A. Russell and M. Zelzer, Analyst, 2016, 141, 90-95.

135 N. Verbeeck, J. M. Spraggins, M. J. M. Murphy, H. D. Wang, A. Y. Deutch, R. M. Caprioli and R. Van de Plas, Biochim. Biophys. Acta, 2017, 1865, 967-977.

136 K. Chughtai, L. Jiang, H. Post, P. T. Winnard Jr., T. R. Greenwood, V. Raman, Z. M. Bhujwalla, R. M. Heeren and K. Glunde, J. Am. Soc. Mass Spectrom., 2013, 24, 711-717.

137 N. H. Patterson, R. J. Doonan, S. S. Daskalopoulou, M. Dufresne, S. Lenglet, F. Montecucco, A. Thomas and P. Chaurand, Proteomics, 2016, 16, 1642-1651.

138 G. Robichaud, K. P. Garrard, J. A. Barry and D. C. Muddiman, J. Am. Soc. Mass Spectrom., 2013, 24, 718-721.

139 K. D. Bemis, A. Harry, L. S. Eberlin, C. Ferreira, S. M. van de Ven, P. Mallick, M. Stolowitz and O. Vitek, Bioinformatics, 2015, 31, 2418-2420.

140 M. F. Robbe, J. P. Both, B. Prideaux, I. Klinkert, V. Picaud, T. Schramm, A. Hester, V. Guevara, M. Stoeckli, A. Roempp, R. M. Heeren, B. Spengler, O. Gala and S. Haan, Eur. J. Mass. Spectrom., 2014, 20, 351-360.

141 P. Kallback, A. Nilsson, M. Shariatgorji and P. E. Andren, Anal. Chem., 2016, 88, 4346-4353.

142 A. M. Race, A. D. Palmer, A. Dexter, R. T. Steven, I. B. Styles and J. Bunch, Anal. Chem., 2016, 88, 94519458.

143 R. Van de Plas, J. Yang, J. Spraggins and R. M. Caprioli, Nat. Methods, 2015, 12, 366-372.

144 A. Cassese, S. R. Ellis, N. Ogrinc Potocnik, E. Burgermeister, M. Ebert, A. Walch, A. M. van den Maagdenberg, L. A. McDonnell, R. M. Heeren and B. Balluff, Anal. Chem., 2016, 88, 5871-5878.

145 P. Widlak, G. Mrukwa, M. Kalinowska, M. Pietrowska, M. Chekan, J. Wierzgon, M. Gawin, G. Drazek and J. Polanska, Proteomics, 2016, 16, 1613-1621.

146 T. Alexandrov and J. H. Kobarg, Bioinformatics, 2011, 27, i230-i238.

147 A. Palmer, P. Phapale, I. Chernyavsky, R. Lavigne, D. Fay, A. Tarasov, V. Kovalev, J. Fuchser, S. Nikolenko, C. Pineau, M. Becker and T. Alexandrov, Nat. Methods, 2017, 14, 57-60.

148 T. Schramm, A. Hester, I. Klinkert, J. P. Both, R. M. Heeren, A. Brunelle, O. Laprevote, N. Desbenoit, M. F. Robbe, M. Stoeckli, B. Spengler and A. Rompp, J. Proteomics, 2012, 75, 5106-5110.

149 A. Rompp, R. Wang, J. P. Albar, A. Urbani, H. Hermjakob, B. Spengler and J. A. Vizcaino, Anal. Bioanal. Chem., 2015, 407, 2027-2033.

150 L. A. McDonnell, A. Rompp, B. Balluff, R. M. Heeren, J. P. Albar, P. E. Andren, G. L. Corthals, A. Walch and M. Stoeckli, Anal. Bioanal. Chem., 2015, 407, 2035-2045.

151 S. Lou, B. Balluff, A. H. G Cleven, J. V. Bovee and L. A. McDonnell, Biochim. Biophys. Acta, 2017, 1865, 957966.
152 R. Lemaire, S. A. Menguellet, J. Stauber, V. Marchaudon, J. P. Lucot, P. Collinet, M. O. Farine, D. Vinatier, R. Day, P. Ducoroy, M. Salzet and I. Fournier, J. Proteome Res., 2007, 6, 4127-4134.

153 R. Longuespee, C. Boyon, C. Castellier, A. Jacquet, A. Desmons, O. Kerdraon, D. Vinatier, I. Fournier, R. Day and M. Salzet, Histochem. Cell Biol., 2012, 138, 141-154.

154 L. H. Cazares, D. Troyer, S. Mendrinos, R. A. Lance, J. O. Nyalwidhe, H. A. Beydoun, M. A. Clements, R. R. Drake and O. J. Semmes, Clin. Cancer Res., 2009, 15, 5541-5551.

155 M. Elsner, S. Rauser, S. Maier, C. Schone, B. Balluff, S. Meding, G. Jung, M. Nipp, H. Sarioglu, G. Maccarrone, M. Aichler, A. Feuchtinger, R. Langer, U. Jutting, M. Feith, B. Kuster, M. Ueffing, H. Zitzelsberger, H. Hofler and A. Walch, J. Proteomics, 2012, 75, 4693-4704.

156 S. Laouirem, J. Le Faouder, T. Alexandrov, D. Mestivier, T. Leger, X. Baudin, M. Mebarki, V. Paradis, J. M. Camadro and P. Bedossa, J. Pathol., 2014, 234, 452463.

157 V. Rebours, J. Le Faouder, S. Laouirem, M. Mebarki, M. Albuquerque, J. M. Camadro, T. Leger, P. Ruszniewski, P. Levy, V. Paradis, P. Bedossa and A. Couvelard, Pancreatology, 2014, 14, 117-124.

158 B. Balluff, M. Elsner, A. Kowarsch, S. Rauser, S. Meding, C. Schuhmacher, M. Feith, K. Herrmann, C. Rocken, R. M. Schmid, H. Hofler, A. Walch and M. P. Ebert, J. Proteome Res., 2010, 9, 6317-6322.

159 S. Meding, B. Balluff, M. Elsner, C. Schone, S. Rauser, U. Nitsche, M. Maak, A. Schafer, S. M. Hauck, M. Ueffing, R. Langer, H. Hofler, H. Friess, R. Rosenberg and A. Walch, J. Pathol., 2012, 228, 459-470.

160 B. Balluff, S. Rauser, S. Meding, M. Elsner, C. Schone, A. Feuchtinger, C. Schuhmacher, A. Novotny, U. Jutting, G. Maccarrone, H. Sarioglu, M. Ueffing, H. Braselmann, H. Zitzelsberger, R. M. Schmid, H. Hofler, M. P. Ebert and A. Walch, Am. J. Pathol., 2011, 179, 2720-2729.

161 T. Gemoll, S. Strohkamp, K. Schillo, C. Thorns and J. K. Habermann, Oncotarget, 2015, 6, 43869-43880.

162 S. Lou, B. Balluff, M. A. de Graaff, A. H. Cleven, I. Briairede Bruijn, J. V. Bovee and L. A. McDonnell, Proteomics, 2016, 16, 1802-1813.

163 L. Chung, L. Phillips, M. Z. Lin, K. Moore, D. J. Marsh, F. M. Boyle and R. C. Baxter, Cancer Lett., 2015, 368, 64-70.

164 W. M. Hardesty, M. C. Kelley, D. Mi, R. L. Low and R. M. Caprioli, J. Proteomics, 2011, 74, 1002-1014.

165 N. Pote, T. Alexandrov, J. Le Faouder, S. Laouirem, T. Leger, M. Mebarki, J. Belghiti, J. M. Camadro, P. Bedossa and V. Paradis, Hepatology, 2013, 58, 983-994.

166 J. A. Bauer, A. B. Chakravarthy, J. M. Rosenbluth, D. Mi, E. H. Seeley, N. De Matos Granja-Ingram, M. G. Olivares, M. C. Kelley, I. A. Mayer, I. M. Meszoely, J. A. MeansPowell, K. N. Johnson, C. J. Tsai, G. D. Ayers, M. E. Sanders, R. J. Schneider, S. C. Formenti, R. M. Caprioli and J. A. Pietenpol, Clin. Cancer Res., 2010, 16, 681-690. 
167 M. Aichler, M. Elsner, N. Ludyga, A. Feuchtinger, V. Zangen, S. K. Maier, B. Balluff, C. Schone, L. Hierber, H. Braselmann, S. Meding, S. Rauser, H. Zischka, M. Aubele, M. Schmitt, M. Feith, S. M. Hauck, M. Ueffing, R. Langer, B. Kuster, H. Zitzelsberger, H. Hofler and A. K. Walch, J. Pathol., 2013, 230, 410-419.

168 R. Lazova, E. H. Seeley, M. Keenan, R. Gueorguieva and R. M. Caprioli, Am. J. Dermatopathol., 2012, 34, 82-90.

169 R. Lazova, E. H. Seeley, H. Kutzner, R. A. Scolyer, G. Scott, L. Cerroni, I. Fried, M. E. Kozovska, A. S. Rosenberg, V. G. Prieto, B. M. Shehata, M. M. Durham, G. Henry, J. L. Rodriguez-Peralto, E. Riveiro-Falkenbach, J. T. Schaefer, R. Danialan, S. Fraitag, S. VollenweiderRoten, A. Sepehr, M. Sangueza, N. Hijazi, Y. Corredoira, R. Kowal, O. M. Harris, F. Bravo, A. S. Boyd, R. Gueorguieva and R. M. Caprioli, J. Am. Acad. Dermatol., 2016, 75, 1176-1186, e1174.

170 S. O. Deininger, M. P. Ebert, A. Futterer, M. Gerhard and C. Rocken, J. Proteome Res., 2008, 7, 5230-5236.

171 B. Balluff, C. K. Frese, S. K. Maier, C. Schone, B. Kuster, M. Schmitt, M. Aubele, H. Hofler, A. M. Deelder, A. Heck Jr., P. C. Hogendoorn, J. Morreau, A. F. Maarten Altelaar, A. Walch and L. A. McDonnell, J. Pathol., 2015, 235, 3-13.

172 I. A. Mulder, C. Esteve, M. J. Wermer, M. Hoehn, E. A. Tolner, A. M. van den Maagdenberg and L. A. McDonnell, Proteomics, 2016, 16, 1652-1659.

173 S. Guenther, L. J. Muirhead, A. V. Speller, O. Golf, N. Strittmatter, R. Ramakrishnan, R. D. Goldin, E. Jones, K. Veselkov, J. Nicholson, A. Darzi and Z. Takats, Cancer Res., 2015, 75, 1828-1837.

174 S. Gerbig, O. Golf, J. Balog, J. Denes, Z. Baranyai, A. Zarand, E. Raso, J. Timar and Z. Takats, Anal. Bioanal. Chem., 2012, 403, 2315-2325.

175 L. S. Eberlin, I. Norton, A. L. Dill, A. J. Golby, K. L. Ligon, S. Santagata, R. G. Cooks and N. Y. Agar, Cancer Res., 2012, 72, 645-654.

176 N. H. Patterson, B. Alabdulkarim, A. Lazaris, A. Thomas, M. M. Marcinkiewicz, Z. H. Gao, P. B. Vermeulen, P. Chaurand and P. Metrakos, Sci. Rep., 2016, 6, 36814.

177 S. Lou, B. Balluff, A. H. Cleven, J. V. Bovee and L. A. McDonnell, J. Am. Soc. Mass Spectrom., 2017, 28, 376-383.

178 R. Mirnezami, K. Spagou, P. A. Vorkas, M. R. Lewis, J. Kinross, E. Want, H. Shion, R. D. Goldin, A. Darzi, Z. Takats, E. Holmes, O. Cloarec and J. K. Nicholson, Mol. Oncol., 2014, 8, 39-49.

179 S. R. Oppenheimer, D. Mi, M. E. Sanders and R. M. Caprioli, J. Proteome Res., 2010, 9, 2182-2190.

180 D. Calligaris, D. R. Feldman, I. Norton, P. K. Brastianos, I. F. Dunn, S. Santagata and N. Y. Agar, Int. J. Mass Spectrom., 2015, 377, 690-698.

181 D. Calligaris, D. Caragacianu, X. Liu, I. Norton, C. J. Thompson, A. L. Richardson, M. Golshan, M. L. Easterling, S. Santagata, D. A. Dillon, F. A. Jolesz and N. Y. Agar, Proc. Natl. Acad. Sci. U. S. A., 2014, 111, 15184-15189.
182 L. S. Eberlin, R. J. Tibshirani, J. Zhang, T. A. Longacre, G. J. Berry, D. B. Bingham, J. A. Norton, R. N. Zare and G. A. Poultsides, Proc. Natl. Acad. Sci. U. S. A., 2014, 111, 2436-2441.

183 L. S. Eberlin, K. Margulis, I. Planell-Mendez, R. N. Zare, R. Tibshirani, T. A. Longacre, M. Jalali, J. A. Norton and G. A. Poultsides, PLoS Med., 2016, 13, e1002108.

184 A. Tata, J. Zheng, H. J. Ginsberg, D. A. Jaffray, D. R. Ifa and A. Zarrine-Afsar, Anal. Chem., 2015, 87, 7683-7689.

185 N. Abbassi-Ghadi, K. Veselkov, S. Kumar, J. Huang, E. Jones, N. Strittmatter, H. Kudo, R. Goldin, Z. Takats and G. B. Hanna, Chem. Commun., 2014, 50, 3661-3664.

186 N. Abbassi-Ghadi, O. Golf, S. Kumar, S. Antonowicz, J. S. McKenzie, J. Huang, N. Strittmatter, H. Kudo, E. A. Jones, K. Veselkov, R. Goldin, Z. Takats and G. B. Hanna, Cancer Res., 2016, 76, 5647-5656.

187 K. S. Kerian, A. K. Jarmusch and R. G. Cooks, Analyst, 2014, 139, 2714-2720.

188 K. S. Kerian, A. K. Jarmusch, V. Pirro, M. O. Koch, T. A. Masterson, L. Cheng and R. G. Cooks, Analyst, 2015, 140, 1090-1098.

189 C. M. Alfaro, A. K. Jarmusch, V. Pirro, K. S. Kerian, T. A. Masterson, L. Cheng and R. G. Cooks, Anal. Bioanal. Chem., 2016, 408, 5407-5414.

190 J. Balog, L. Sasi-Szabo, J. Kinross, M. R. Lewis, L. J. Muirhead, K. Veselkov, R. Mirnezami, B. Dezso, L. Damjanovich, A. Darzi, J. K. Nicholson and Z. Takats, Sci. Transl. Med., 2013, 5, 194ra193.

191 J. Alexander, L. Gildea, J. Balog, A. Speller, J. McKenzie, L. Muirhead, A. Scott, C. Kontovounisios, S. Rasheed, J. Teare, J. Hoare, K. Veselkov, R. Goldin, P. Tekkis, A. Darzi, J. Nicholson, J. Kinross and Z. Takats, Surg. Endosc., 2017, 31, 1361-1370.

192 J. Balog, S. Kumar, J. Alexander, O. Golf, J. Huang, T. Wiggins, N. Abbassi-Ghadi, A. Enyedi, S. Kacska, J. Kinross, G. B. Hanna, J. K. Nicholson and Z. Takats, Angew. Chem., Int. Ed. Engl., 2015, 54, 11059-11062.

193 B. Fatou, P. Saudemont, E. Leblanc, D. Vinatier, V. Mesdag, M. Wisztorski, C. Focsa, M. Salzet, M. Ziskind and I. Fournier, Sci. Rep., 2016, 6, 25919.

194 V. Pirro, L. S. Eberlin, P. Oliveri and R. G. Cooks, Analyst, 2012, 137, 2374-2380.

195 S. Meding, U. Nitsche, B. Balluff, M. Elsner, S. Rauser, C. Schone, M. Nipp, M. Maak, M. Feith, M. P. Ebert, H. Friess, R. Langer, H. Hofler, H. Zitzelsberger, R. Rosenberg and A. Walch, J. Proteome Res., 2012, 11, 1996-2003.

196 L. S. Eberlin, M. Gabay, A. C. Fan, A. M. Gouw, R. J. Tibshirani, D. W. Felsher and R. N. Zare, Proc. Natl. Acad. Sci. U. S. A., 2014, 111, 10450-10455.

197 B. M. Grüner, H. Hahne, P. K. Mazur, M. Trajkovic-Arsic, S. Maier, I. Esposito, E. Kalideris, C. W. Michalski, J. Kleeff, S. Rauser, R. M. Schmid, B. Kuster, A. Walch and J. T. Siveke, PLoS One, 2012, 7, e39424.

198 B. M. Grüner, I. Winkelmann, A. Feuchtinger, N. Sun, B. Balluff, N. Teichmann, A. Herner, E. Kalideris, 
K. Steiger, R. Braren, M. Aichler, I. Esposito, R. M. Schmid, A. Walch and J. T. Siveke, Mol. Cancer Ther., 2016, 15, 1145-1152.

199 N. Desbenoit, I. Schmitz-Afonso, C. Baudouin, O. Laprevote, D. Touboul, F. Brignole-Baudouin and A. Brunelle, Anal. Bioanal. Chem., 2013, 405, 4039-4049.

200 M. R. Groseclose, S. B. Laffan, K. S. Frazier, A. HughesEarle and S. Castellino, J. Am. Soc. Mass Spectrom., 2015, 26, 887-898.

201 T. Yoshimi, S. Kawabata, S. Taira, A. Okuno, R. Mikawa, S. Murayama, K. Tanaka and O. Takikawa, Analyst, 2015, 140, 7202-7208.

202 J. Hanrieder and A. G. Ewing, Sci. Rep., 2014, 4, 5266.

203 A. N. Lazar, C. Bich, M. Panchal, N. Desbenoit, V. W. Petit, D. Touboul, L. Dauphinot, C. Marquer, O. Laprevote, A. Brunelle and C. Duyckaerts, Acta Neuropathol., 2013, 125, 133-144.

204 L. H. Mendis, A. C. Grey, R. L. Faull and M. A. Curtis, Brain Behav., 2016, 6, e00517.

205 R. J. Carreira, R. Shyti, B. Balluff, W. M. Abdelmoula, S. H. van Heiningen, R. J. van Zeijl, J. Dijkstra, M. D. Ferrari, E. A. Tolner, L. A. McDonnell and A. M. van den Maagdenberg, J. Am. Soc. Mass Spectrom., 2015, 26, 853-861.

206 G. A. Sarkis, M. D. Mangaonkar, A. Moghieb, B. Lelling, M. Guertin, H. Yadikar, Z. Yang, F. Kobeissy and K. K. Wang, Curr. Neurol. Neurosci. Rep., 2017, 17, 23.

207 A. Ljungdahl, J. Hanrieder, M. Falth, J. Bergquist and M. Andersson, PLoS One, 2011, 6, e25653.

208 K. Skold, M. Svensson, A. Nilsson, X. Zhang, K. Nydahl, R. M. Caprioli, P. Svenningsson and P. E. Andren, J. Proteome Res., 2006, 5, 262-269.

209 J. Pierson, J. L. Norris, H. R. Aerni, P. Svenningsson, R. M. Caprioli and P. E. Andren, J. Proteome Res., 2004, 3, 289-295.

210 J. Matsumoto, Y. Sugiura, D. Yuki, T. Hayasaka, N. GotoInoue, N. Zaima, Y. Kunii, A. Wada, Q. Yang, K. Nishiura, H. Akatsu, A. Hori, Y. Hashizume, T. Yamamoto, K. Ikemoto, M. Setou and S. Niwa, Anal. Bioanal. Chem., 2011, 400, 1933-1943.

211 M. Dufresne, D. Guneysu, N. H. Patterson, M. M. Marcinkiewicz, A. Regina, M. Demeule and P. Chaurand, Anal. Bioanal. Chem., 2017, 409, 1425-1433.

212 V. Llombart, S. A. Trejo, S. Bronsoms, A. Morancho, M. Feifei, J. Faura, T. Garcia-Berrocoso, A. Simats, A. Rosell, F. Canals, M. Hernandez-Guillamon and J. Montaner, J. Proteomics, 2017, 152, 243-253.

213 M. Shariatgorji, P. Svenningsson and P. E. Andren, Neuropsychopharmacology, 2014, 39, 34-49.

214 K. O. Schubert, F. Weiland, B. T. Baune and P. Hoffmann, Proteomics, 2016, 16, 1747-1758.

215 M. Martin-Lorenzo, B. Balluff, A. S. Maroto, R. J. Carreira, R. J. van Zeijl, L. Gonzalez-Calero, F. de la Cuesta, M. G. Barderas, L. F. Lopez-Almodovar, L. R. Padial, L. A. McDonnell, F. Vivanco and G. Alvarez-Llamas, J. Proteomics, 2015, 126, 245-251.
216 M. Martin-Lorenzo, G. Alvarez-Llamas, L. A. McDonnell and F. Vivanco, Expert Rev. Proteomics, 2016, 13, 69-81.

217 M. Aichler, K. Huber, F. Schilling, F. Lohofer, K. Kosanke, R. Meier, E. J. Rummeny, A. Walch and M. Wildgruber, Angew. Chem., Int. Ed. Engl., 2015, 54, 4279-4283.

218 L. Mourino-Alvarez, I. Iloro, F. de la Cuesta, M. Azkargorta, T. Sastre-Oliva, I. Escobes, L. F. LopezAlmodovar, P. L. Sanchez, H. Urreta, F. Fernandez-Aviles, A. Pinto, L. R. Padial, F. Akerstrom, F. Elortza and M. G. Barderas, Sci. Rep., 2016, 6, 27106.

219 P. M. Angel, H. S. Baldwin, D. Gottlieb Sen, Y. R. Su, J. E. Mayer, D. Bichell and R. R. Drake, Biochim. Biophys. Acta, 2017, 1865, 927-935.

220 B. Rocha, C. Ruiz-Romero and F. J. Blanco, Nat. Rev. Rheumatol., 2017, 13, 52-63.

221 M. T. Briggs, J. S. Kuliwaba, D. Muratovic, A. V. EverestDass, N. H. Packer, D. M. Findlay and P. Hoffmann, Proteomics, 2016, 16, 1736-1741.

222 B. Cillero-Pastor, G. Eijkel, A. Kiss, F. J. Blanco and R. M. Heeren, Anal. Chem., 2012, 84, 8909-8916.

223 B. Cillero-Pastor, G. B. Eijkel, F. J. Blanco and R. M. Heeren, Anal. Bioanal. Chem., 2015, 407, 2213-2222.

224 B. Rocha, B. Cillero-Pastor, G. Eijkel, A. L. Bruinen, C. Ruiz-Romero, R. M. Heeren and F. J. Blanco, Proteomics, 2015, 15, 702-713.

225 N. Georgi, B. Cillero-Pastor, G. B. Eijkel, P. C. Periyasamy, A. Kiss, C. van Blitterswijk, J. N. Post, R. M. Heeren and M. Karperien, Anal. Chem., 2015, 87, 3981-3988.

226 M. J. Peffers, B. Cillero-Pastor, G. B. Eijkel, P. D. Clegg and R. M. Heeren, Arthritis Res. Ther., 2014, 16, R110.

227 V. Mainini, F. Pagni, F. Ferrario, F. Pieruzzi, M. Grasso, A. Stella, G. Cattoretti and F. Magni, Histopathology, 2014, 64, 901-906.

228 A. Smith, V. L'Imperio, G. De Sio, F. Ferrario, C. Scalia, G. Dell'Antonio, F. Pieruzzi, C. Pontillo, S. Filip, K. Markoska, A. Granata, G. Spasovski, J. Jankowski, G. Capasso, F. Pagni and F. Magni, Proteomics, 2016, 16, 1759-1766.

229 R. Casadonte, M. Kriegsmann, S. O. Deininger, K. Amann, R. Paape, E. Belau, D. Suckau, J. Fuchser, J. Beckmann, M. Becker and J. Kriegsmann, Anal. Bioanal. Chem., 2015, 407, 5323-5331.

230 M. Winter, A. Tholey, S. Kruger, H. Schmidt and C. Rocken, J. Histochem. Cytochem., 2015, 63, 772-779.

231 H. E. Bowrey, D. M. Anderson, P. Pallitto, D. B. Gutierrez, J. Fan, R. K. Crouch, K. L. Schey and Z. Ablonczy, Proteomics Clin. Appl., 2016, 10, 391-402.

232 R. K. Crouch, Y. Koutalos, M. Kono, K. Schey and Z. Ablonczy, Prog. Mol. Biol. Transl. Sci., 2015, 134, 449-463.

233 M. A. Yakovleva, A. A. Gulin, T. B. Feldman, Y. C. Bel'skich, P. M. Arbukhanova, A. A. Astaf'ev, V. A. Nadtochenko, S. A. Borzenok and M. A. Ostrovsky, Anal. Bioanal. Chem., 2016, 408, 7521-7528.

234 D. M. Anderson, Z. Ablonczy, Y. Koutalos, J. Spraggins, R. K. Crouch, R. M. Caprioli and K. L. Schey, J. Am. Soc. Mass Spectrom., 2014, 25, 1394-1403. 
235 F. Brignole-Baudouin, N. Desbenoit, G. Hamm, H. Liang, J. P. Both, A. Brunelle, I. Fournier, V. Guerineau, R. Legouffe, J. Stauber, D. Touboul, M. Wisztorski, M. Salzet, O. Laprevote and C. Baudouin, PLoS One, 2012, 7, e50180.

236 M. G. Nye-Wood, J. M. Spraggins, R. M. Caprioli, K. L. Schey, P. J. Donaldson and A. C. Grey, Exp. Eye Res., 2017, 154, 70-78.

237 N. Sun, A. Ly, S. Meding, M. Witting, S. M. Hauck, M. Ueffing, P. Schmitt-Kopplin, M. Aichler and A. Walch, Proteomics, 2014, 14, 913-923.

238 D. Taverna, A. C. Pollins, G. Sindona, R. M. Caprioli and L. B. Nanney, J. Proteome Res., 2015, 14, 986-996.

239 D. Taverna, A. C. Pollins, G. Sindona, R. M. Caprioli and L. B. Nanney, Wound Repair Regen., 2016, 24, 775-785.

240 C. L. Bowlus, E. H. Seeley, J. Roder, J. Grigorieva, H. Roder, R. M. Caprioli and M. Gershwin, Cell. Mol. Immunol., 2011, 8, 237-242.

241 R. Clarke, H. W. Ressom, A. Wang, J. Xuan, M. C. Liu, E. A. Gehan and Y. Wang, Nat. Rev. Cancer, 2008, 8, 37-49.

242 D. F. Ransohoff, Nat. Rev. Cancer, 2004, 4, 309-314.

243 F. Lehmann, D. Lacombe, P. Therasse and A. M. Eggermont, J. Transl. Med., 2003, 1, 2.

244 M. Kriegsmann, R. Casadonte, J. Kriegsmann, H. Dienemann, P. Schirmacher, J. Hendrik-Kobarg, K. Schwamborn, A. Stenzinger, A. Warth and W. Weichert, Mol. Cell. Proteomics, 2016, 15, 3081-3089.
245 S. Michiels, S. Koscielny and C. Hill, Lancet, 2005, 365, 488-492.

246 N. H. Patterson, A. Thomas and P. Chaurand, J. Mass Spectrom., 2014, 49, 622-627.

247 R. J. Goodwin, J. Proteomics, 2012, 75, 4893-4911.

248 R. J. Goodwin, J. C. Dungworth, S. R. Cobb and A. R. Pitt, Proteomics, 2008, 8, 3801-3808.

249 A. L. Dill, L. S. Eberlin, A. B. Costa, D. R. Ifa and R. G. Cooks, Anal. Bioanal. Chem., 2011, 401, 1949-1961.

250 W. B. Parson, S. L. Koeniger, R. W. Johnson, J. Erickson, Y. Tian, C. Stedman, A. Schwartz, E. Tarcsa, R. Cole and G. J. Van Berkel, J. Mass Spectrom., 2012, 47, 1420-1428.

251 W. M. Abdelmoula, K. Skraskova, B. Balluff, R. J. Carreira, E. A. Tolner, B. P. Lelieveldt, L. van der Maaten, H. Morreau, A. M. van den Maagdenberg, R. M. Heeren, L. A. McDonnell and J. Dijkstra, Anal. Chem., 2014, 86, 9204-9211.

252 R. D. Addie, B. Balluff, J. V. Bovee, H. Morreau and L. A. McDonnell, Anal. Chem., 2015, 87, 6426-6433.

253 J. M. Wiseman, D. R. Ifa, Q. Song and R. G. Cooks, Angew. Chem., Int. Ed., 2006, 45, 7188-7192.

254 A. L. Dill, D. R. Ifa, N. E. Manicke, A. B. Costa, J. A. Ramos-Vara, D. W. Knapp and R. G. Cooks, Anal. Chem., 2009, 81, 8758-8764.

255 D. M. Rubio, E. E. Schoenbaum, L. S. Lee, D. E. Schteingart, P. R. Marantz, K. E. Anderson, L. D. Platt, A. Baez and K. Esposito, Acad. Med., 2010, 85, $470-475$. 